\title{
On the Nature and Variability of the East Greenland Spill Jet: A Case Study in Summer 2003*
}

\author{
M. G. Magaldi And T. W. N. Haine \\ Department of Earth and Planetary Sciences, The Johns Hopkins University, Baltimore, Maryland \\ R. S. PICKART \\ Woods Hole Oceanographic Institution, Woods Hole, Massachusetts
}

(Manuscript received 6 November 2010, in final form 7 July 2011)

\begin{abstract}
Results from a high-resolution $(\sim 2 \mathrm{~km})$ numerical simulation of the Irminger Basin during summer 2003 are presented. The focus is on the East Greenland Spill Jet, a recently discovered component of the circulation in the basin. The simulation compares well with observations of surface fields, the Denmark Strait overflow (DSO), and the hydrographic structure of typical sections in the basin. The model reveals new aspects of the circulation on scales of $O(0.1-10)$ days and $O(1-100) \mathrm{km}$.

The model Spill Jet results from the cascade of dense waters over the East Greenland shelf. Spilling can occur in various locations southwest of the strait, and it is present throughout the simulation but exhibits large variations on periods of $O(0.1-10)$ days. The Spill Jet sometimes cannot be distinguished in the velocity field from surface eddies or from the DSO. The vorticity structure of the jet confirms its unstable nature with peak relative and tilting vorticity terms reaching twice the planetary vorticity term.

The average model Spill Jet transport is $4.9 \pm 1.7 \mathrm{~Sv}\left(1 \mathrm{~Sv} \equiv 10^{6} \mathrm{~m}^{3} \mathrm{~s}^{-1}\right)$ equatorward, about $2 \frac{1}{2}$ times larger than has been previously reported from a single ship transect in August 2001. Kinematic analysis of the model results suggests two different types of spilling events. In the first case (type I), a local perturbation results in dense waters descending over the shelf break into the Irminger Basin. In the second case (type II), surface cyclones associated with DSO deep domes initiate the spilling process. During summer 2003, more than half of the largest Spill Jet transport values are of type II.
\end{abstract}

\section{Introduction}

The Irminger Basin is located south of Denmark Strait, between southeast Greenland and the Reykjanes Ridge (Fig. 1a). It is dynamically relevant to North Atlantic Ocean circulation and ultimately to the global climate system because dense North Atlantic water masses are formed and transformed within the basin. For example, the Irminger Basin is one of the few locations where deep convection can take place and form a homogeneous

\footnotetext{
* Supplemental information related to this paper is available at the Journals Online Web site: http://dx.doi.org/10.1175/JPO-D-1005004.s1.

Corresponding author address: M. G. Magaldi, Department of Earth and Planetary Sciences, The Johns Hopkins University, Olin Hall, 34th and North Charles Streets, Baltimore, MD 21218. E-mail: marcello.magaldi@jhu.edu
}

water mass very similar to Labrador Seawater (LSW; Pickart et al. 2003; Våge et al. 2008). Furthermore, the Irminger Basin is a region of confluence and mixing of different water masses (cf. Fig. 1 of Pickart et al. 2005, hereafter PTF05). Cold and fresh Arctic waters enter the basin via the Denmark Strait in the upper layer within the East Greenland Current (EGC) and at depth in the Denmark Strait overflow (DSO). The cold and fresh East Greenland Coastal Current progresses equatorward in the inner portion of the southern Greenland shelf (Bacon et al. 2002; Sutherland and Pickart 2008). Warm and salty Atlantic waters enter from the south and progress cyclonically around the basin in the Irminger Current (IC). At intermediate depths, the basin is filled with LSW because of a combination of local production and remote advection from the Labrador Basin (Straneo et al. 2003; Yashayaev et al. 2007).

The final Irminger Basin water products are determined by stirring and mixing processes that exchange 
(a)

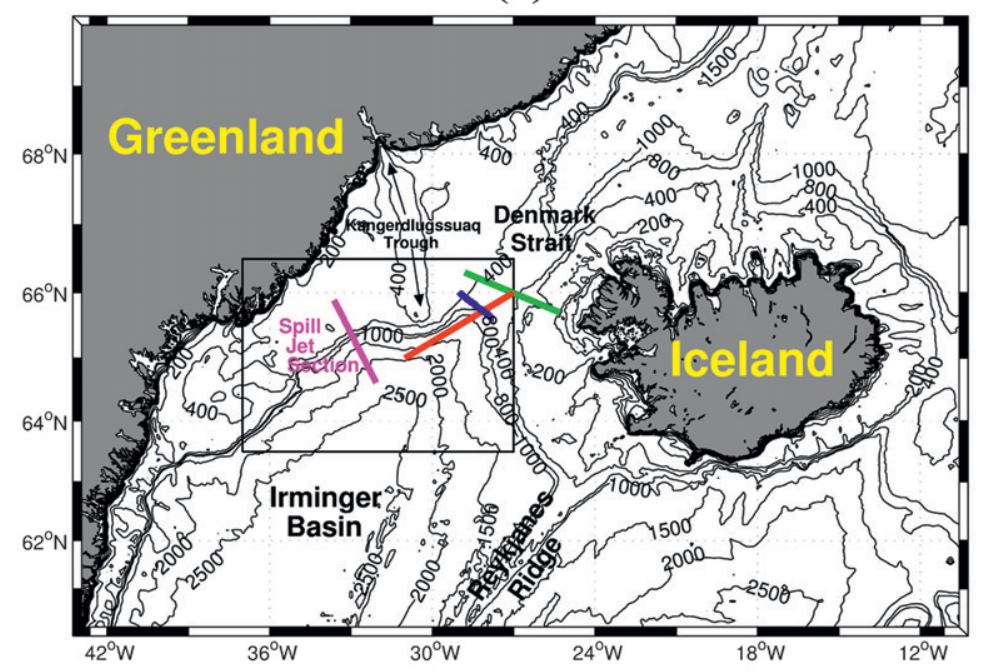

(b)

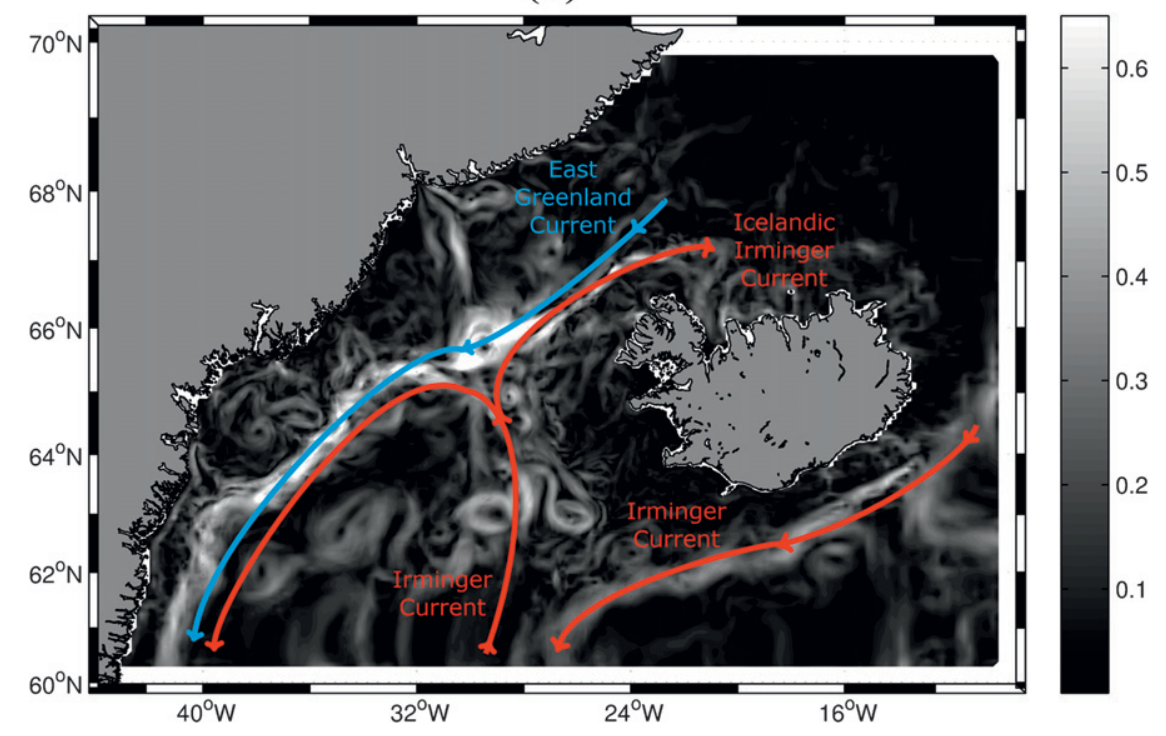

FIG. 1. (a) Plan view of the numerical domain. The 20-, 40-, 60-, 80-, 100-, 200-, 400-, 800-, 1000-, 1500-, 2000-, and 2500-m isobaths are shown. Colored lines denote sections discussed below: in green is the section across Denmark Strait used by Macrander et al. (2007); in red is the thalweg section used by Käse et al. (2003); in blue is the DSS section used by Ross (1977); and in magenta is the Spill Jet section used by PTF05. The box denotes the close-up area discussed in section 3. (b) Schematic of the currents in the upper layer superimposed on the model depth-averaged speed $\left(\mathrm{m} \mathrm{s}^{-1}\right.$ ) on 6 Aug 2003. Red (blue) stands for warm (cold) currents.

properties among the above-mentioned water masses. These processes remain largely unknown, however, because high-resolution sampling both in space and in time is needed to resolve them. This is difficult to achieve in an area that is often inaccessible because of ice and inclement weather. For example, there is evidence that the boundary dividing the East Greenland and Irminger Currents is variable and complex, affected by meanders of the currents and their eddies (see PTF05, and references therein). Moreover, the overflow of the densest waters at the Denmark Strait varies strongly on periods of $O(1)$ days, associated with intense cyclonic boluses (Bruce 1995; Spall and Price 1998; Käse et al. 2003). The overflow is also subject to both vertical shear instabilities and lateral stirring, which lead to entrainment and mixing within the basin. 
In this paper, we focus on a recently discovered phenomenon that may play an important role in the exchanges within the basin. High-resolution observations taken in summer 2001 by PTF05 have detected a narrow (10-15 km) and strong $\left(>0.6 \mathrm{~m} \mathrm{~s}^{-1}\right)$ equatorward flow south of Denmark Strait, banked against the upper continental slope, between the break in the continental shelf and a depth of $1000 \mathrm{~m}$. The current has been named the East Greenland Spill Jet. Its existence was previously hypothesized by Rudels et al. (2002), who observed evidence of dense waters cascading over the shelf break. PTF05 have shown that the Spill Jet is associated with enhanced vertical mixing and have estimated its transport to be roughly $2 \mathrm{~Sv}\left(1 \mathrm{~Sv} \equiv 10^{6} \mathrm{~m}^{3} \mathrm{~s}^{-1}\right)$ to the south. To assess the role played by the Spill Jet in the water-mass exchanges, a comprehensive joint observational-modeling project is underway. The present article is the first step for the high-resolution modeling component of that project. We present a numerical solution that is the finest resolved and most realistic simulation of the Irminger Basin to date.

To advance our understanding of the Spill Jet, two initial priorities are as follows: 1) the reliability of the numerical model needs to be checked, and 2) the synoptic view of the Spill Jet provided by PTF05 needs to be extended in time and space. Specifically, the questions regarding the Irminger Basin dynamics addressed in this work are as follows: 1) How realistic is the simulated circulation using a state-of-the-art high-resolution model? 2) Can the model reproduce the observed variability (e.g., that of the DSO)? 3) How does the model hydrographic structure compare with hydrographic sections in the area? Furthermore, because the main purpose is a more extensive space/time description of the East Greenland Spill Jet, we also ask the following: 4) Is the Spill Jet a permanent feature? 5) Does its spatial location vary, and what is its vertical extent? 6) Is the Spill Jet always distinct from the DSO as in PTF05? 7) How does its transport vary in space and time?

To address these questions, we focus on the summer of 2003. The reason is practical: in 2003, for the first time, observations were made at the Spill Jet location that better resolved the details of the spilling process. Furthermore, in summer 2003, Arctic sea ice extent was almost as low as in 2002, when it reached the lowest level recorded since 1978 (Serreze et al. 2003). Sea ice dynamics are therefore neglected in the present simulations.

It is found that the East Greenland Spill Jet plays an important role in mixing Atlantic- and Arctic-origin waters in the basin. The transport of the jet is subject to variability on periods of $O(0.1-10)$ days, and its average during summer 2003 is roughly $5 \mathrm{~Sv}$ to the south. Although this value is larger than the synoptic estimate of 2001 , it is comparable to the mean transport over multiple occupations of the current (Brearley et al. 2011, manuscript submitted to Deep-Sea Res.). Importantly, it is comparable with the DSO at this location.

The paper is organized as follows: in section 2, the numerical setup and the data collection methods are described. Results from the numerical simulation are presented in section 3. Specifically, model fields are compared to observations in sections $3 \mathrm{a}$ and $3 \mathrm{~b}$, whereas the model Spill Jet data are presented and analyzed in section 3c. Finally, conclusions are given in section 4 .

\section{Methods}

\section{a. Numerical setup}

The dynamics in the Irminger Basin are simulated using the Massachusetts Institute of Technology general circulation model (MITgcm; Marshall et al. 1997), which is chosen for multiple reasons. First, it can accurately simulate fluid motion over steep topography, because of the use of partial bottom "shaved" cells (Adcroft et al. 1997) and a vertical grid that follows the rescaled height coordinate $z^{*}$ (Adcroft and Campin 2004). Second, the MITgcm includes the flow-dependent Leith biharmonic viscosity (Leith 1967, 1996). Unlike the more common Smagorinsky scheme (Smagorinsky 1963), the Leith parameterization simulates the forward enstrophy cascade by making the viscosity proportional to the horizontal gradient of relative vorticity. This viscosity is scale selective and yields more inertial solutions than the Smagorinsky method (Fox-Kemper and Menemenlis 2008). Third, the MITgcm has useful features that will be exploited in the future: namely, its nonhydrostatic capability and the packages to simulate snow and sea ice dynamics (Zhang et al. 1999; Zhang and Rothrock 2000). Finally, previous configurations have been already set up in the same area (Lea et al. 2006; Haine et al. 2009; Haine 2010).

In this study, the hydrostatic configuration of the model is applied and a nonlinear free surface is used (Campin et al. 2004). The realistic (but simplified) equation of state is due to Jackett and McDougall (1995), whereas advection for tracers is computed via a third-order direct spacetime flux limited scheme with zero explicit diffusivity. The $K$-profile parameterization (KPP; Large et al. 1994) is used with a background vertical viscosity of $\nu_{V}=10^{-5} \mathrm{~m}^{2} \mathrm{~s}^{-1}$.

The numerical domain is shown in Fig. 1a and is discretized with an unevenly spaced grid of $540 \times 360$ points. The mesh size increases in both directions moving away from the area of interest. The most resolved interior area around the Spill Jet section (magenta line in Fig. 1a) includes the Denmark Strait and has a nominal horizontal resolution of less than $2 \mathrm{~km}$. Open boundaries are located at the north, south, and east of the domain, whereas the western boundary is closed because of the presence of 
Greenland. The bathymetry is interpolated from the new 2-km-resolution International Bathymetric Chart of the Arctic Ocean (IBCAO; Jakobsson et al. 2008). The vertical dimension is discretized by 97 levels with 2-m resolution at the surface and $200-\mathrm{m}$ resolution at $3300 \mathrm{~m}$. This discretization gives 58 levels in the upper $1000 \mathrm{~m}$ and 87 levels in the upper $2000 \mathrm{~m}$. No-slip conditions are applied to all material boundaries.

A coarse-resolution simulation is used to spin up the model. In this configuration, the grid is 4 times coarser (nominal horizontal resolution of less than $8 \mathrm{~km}$ ) and the model has walls instead of open boundaries as in Haine et al. (2009) and Haine (2010). Initial velocity and perturbation sea surface height fields are zero, whereas initial conditions for temperature and salinity are derived from a long-term average of hydrographic data from the International Council for the Exploration of the Sea database (ICES; see http://www.ices.dk/ocean/). The tracer fields are also relaxed to these data at the surface and within a distance of 10 grid points near the closed boundaries. Atmospheric forcing is achieved by periodically using the Comprehensive Ocean-Atmosphere Data Set (COADS) climatological monthly-mean fields (Da Silva et al. 1994). The spin up run lasts for 17 months and the final fields represent the start of the climatological month of June. They are then interpolated and used as initial conditions for the subsequent finer grid run.

The finer 2-km simulation is forced at three open boundaries and the sea surface. Boundary conditions for tracers and velocities are obtained from the $1 / 12^{\circ}$ North Atlantic experiment of the Hybrid Coordinate Ocean Model (HYCOM; Chassignet et al. 2009, and references therein). The interior MITgcm fields are nudged to the HYCOM boundary values within 20 points of the grid edge. The nudging time scale is 1 day at the boundary and linearly increases toward the interior to reach the maximum value of 10 days. A simple no-gradient condition (see Chapman 1985) is used for the sea surface height, whereas the normal velocities are imposed in order to ensure no net inflow. Surface boundary conditions are derived from the 6-hourly global National Centers for Environmental Prediction (NCEP) reanalysis surface fluxes (Kalnay et al. 1996). The composite (mainly satellite-derived), blended SeaWinds product (Zhang et al. 2006) is preferred to the NCEP wind field because it has higher resolution $\left(0.25^{\circ}\right.$ instead of $\left.2.5^{\circ}\right)$ and because NCEP is known to underestimate wind intensity in this area (e.g., Renfrew et al. 2009). Momentum, freshwater, and sensible and latent heat fluxes are all calculated by the model using the atmospheric data and the surface model state via Large and Pond $(1981,1982)$ bulk formulae. In addition, the temperature of the surface layer is relaxed to the Polar Science Center hydrographic monthly-mean sea surface temperature (SST) climatology (PHC3.0; updated from Steele et al. 2001) with a 5-day time scale. No surface relaxation is imposed to the salinity field. The simulated period is between 1 June and 1 September 2003 , but only the last 2 months are considered.

\section{b. Observational data}

The data used in this study were collected during voyage 395 of the R/V Oceanus from 27 July to 10 August 2003. During the cruise, three hydrographic-velocity sections were occupied across the continental shelf and slope equatorward of Denmark Strait to investigate the presence and character of the East Greenland Spill Jet. The sections were separated by $45 \mathrm{~km}$, with high cross-stream resolution of stations (during the upstream section, stations were occupied less than $1.5 \mathrm{~km}$ apart in order to resolve the detailed structure of the jet). In the present paper, we consider only the central section, which was a reoccupation of the 2001 Spill Jet line (magenta line in Fig. 1a). The full survey took roughly 2.5 days to complete. The reader is referred to Brearley et al. (2011, manuscript submitted to Deep-Sea Res.) for a detailed description of how hydrographic and absolute velocity measurements were obtained.

\section{Results}

In this section, the model fields are at first compared to the observations in summer 2003. The focus is initially on surface fields and the Denmark Strait overflow waters. A direct comparison between the measured and modeled fields at the Spill Jet section is then provided. The synoptic observations are put into temporal context with the help of the model. Finally, we discuss the kinematic sequence of spilling events, present the Spill Jet transport time series, and investigate the Spill Jet vorticity structure.

\section{a. Surface fields}

Figure 2 shows model and satellite-derived observed surface fields for 6 August: that is, during the time period when the observations at the Spill Jet section were made. If not indicated otherwise, the figures correspond to 0000 UTC. The model circulation is essentially the same as described in PTF05. In the southern portion of the domain, warm and salty Atlantic waters enter from the boundaries at the east and south and flow around the flanks of the Reykjanes Ridge in the Irminger Current. Just south of Denmark Strait, the Irminger Current separates into two branches, as evident in Fig. 1b. The first branch enters the Denmark Strait and continues northeastward along the Iceland Shelf forming the Icelandic Irminger Current (Jónsson and Briem 2003). The other branch retroflects, follows the shelf break of the western Irminger Basin, and finally exits the domain at the 
(a) Model depth-averaged speed $\left(\mathrm{m} \mathrm{s}^{-1}\right)$

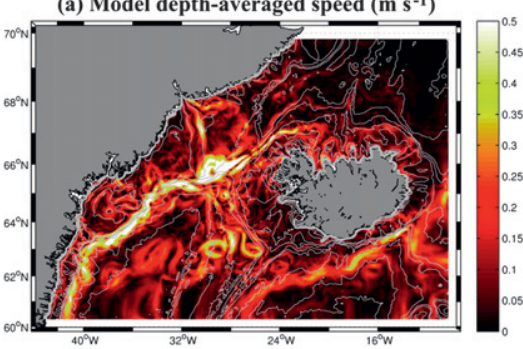

(d) Model sea surface salinity

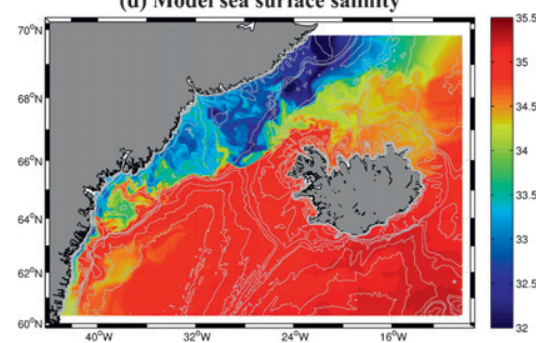

(b) Model sea surface height (m)

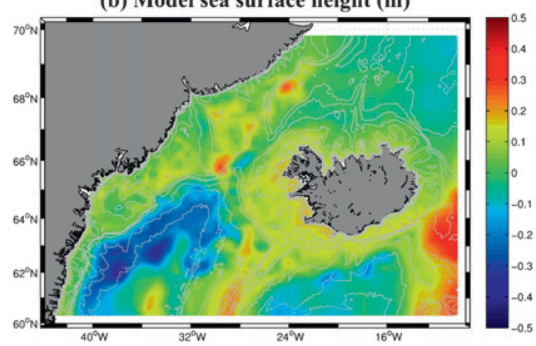

(e) Model sea surface temperature $\left({ }^{\circ} \mathrm{C}\right)$

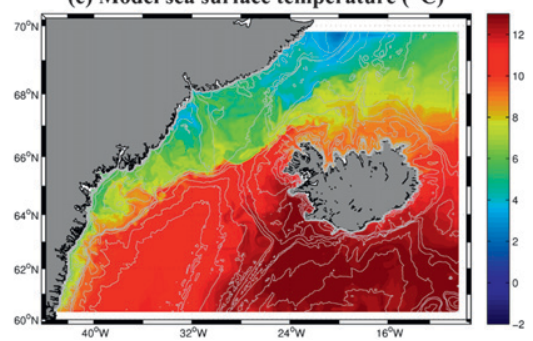

(c) Observed sea surface height anomaly (m)

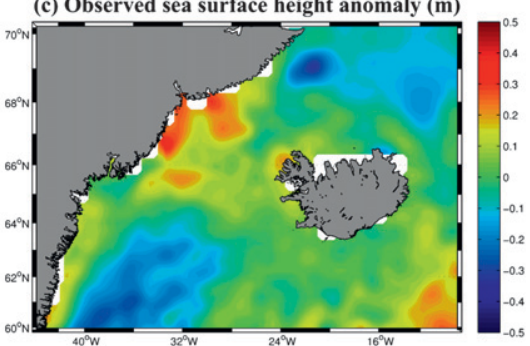

(f) Observed sea surface temperature $\left({ }^{\circ} \mathrm{C}\right)$

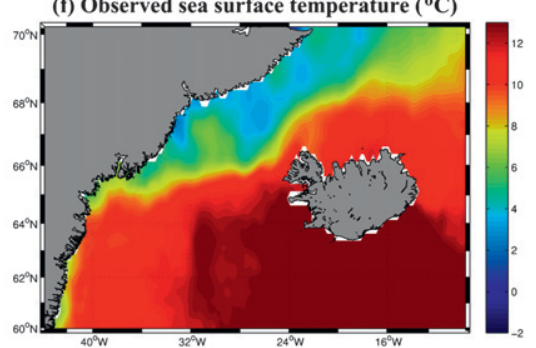

FIG. 2. (a),(b),(d),(e) Modeled and (c),(f) satellite-observed surface fields for 6 Aug 2003. (c) The observed sea surface height anomaly is from the Archiving, Validation and Interpretation of Satellite Oceanographic, Near-Real Time data (AVISO-NRT; see http://www. aviso.oceanobs.com). The anomaly is calculated by subtracting the averaged value throughout the domain and over the entire simulation period. (f) The observed SST is from the Group for High Resolution SST product (GHRSST; see http://ghrsst.nodc.noaa.gov). Gray lines indicate the same isobaths as in Fig. 1a.

southwest corner. In the southwestern quadrant of the numerical domain, a large-scale cyclonic circulation is thus established and corresponding low sea level values are visible in Fig. $2 \mathrm{~b}$ and in the satellite-derived fields (Fig. 2c).

Cold and fresh Arctic waters enter the domain from the north. Some of these waters remain confined to the wide northern portion of the Greenland shelf, whereas some enter the Denmark Strait (Figs. 2d,e). At the surface, waters flow southwestward through the strait in the East Greenland Current. South of Denmark Strait, the East Greenland Current merges with the recirculating Irminger Current branch to form the strong East Greenland-Irminger front, situated more or less at the shelf break. At depth, dense waters overflow at the Denmark Strait sill, as described in section $3 b$.

The comparisons of Fig. 2b with Fig. 2c and of Fig. 2e with Fig. 2f give confidence in the model, because the simulated fields are in good agreement with the observed satellite products. However, the model sea level on 6 August in the Kangerdlugssuaq Trough area is lower than in the observations. The lower sea level in the model is due to model Kelvin waves from the north that are propagating along the Greenland coast and depressing sea level there. The model sea level in this area is similar to the observations at other times (e.g., on 1, 7, and 10 August; not shown). The model also tends to underestimate the surface temperatures north of Iceland, probably because of the coarser mesh in that portion of the domain.
Figure 3 shows cyclonic eddies leaving Denmark Strait and propagating along the continental slope downstream during 5-10 August. These eddies closely resemble those observed in the satellite thermal imagery of Bruce (1995) (see also Fig. 13 of Munk et al. 2000) and are shown to be related to pulses of dense overflow water present at depth (Griffiths 1983; Whitehead et al. 1990). Their intensification happens through vortex stretching downstream of the sill (Spall and Price 1998; Käse et al. 2003).

The eddy propagation strongly influences the dynamics at the Spill Jet (magenta) section. For example, the position of the front separating cold and warm waters at this section remains almost the same during the first 3 days. After that, the front location varies from day to day as eddies pass by. Specifically, the 6 August field (Fig. 3b) shows two cyclonic disturbances upstream of the Spill Jet section (black and yellow arrows). The first cyclone passes the Spill Jet section on 8 August. The leading edge of the second cyclone is impinging on the Spill Jet section on 10 August.

\section{b. Denmark Strait overflow waters}

Figure 4 shows the simulated hydrographic fields for the section across the Denmark Strait sill (green line in Fig. 1a) on 6 August. The section corresponds to that shown in Fig. 1 of Macrander et al. (2007). The model fields closely resemble those observed. DSO waters (potential density $\sigma_{\theta} \geq 27.80 \mathrm{~kg} \mathrm{~m}^{-3}$ ) are banked 

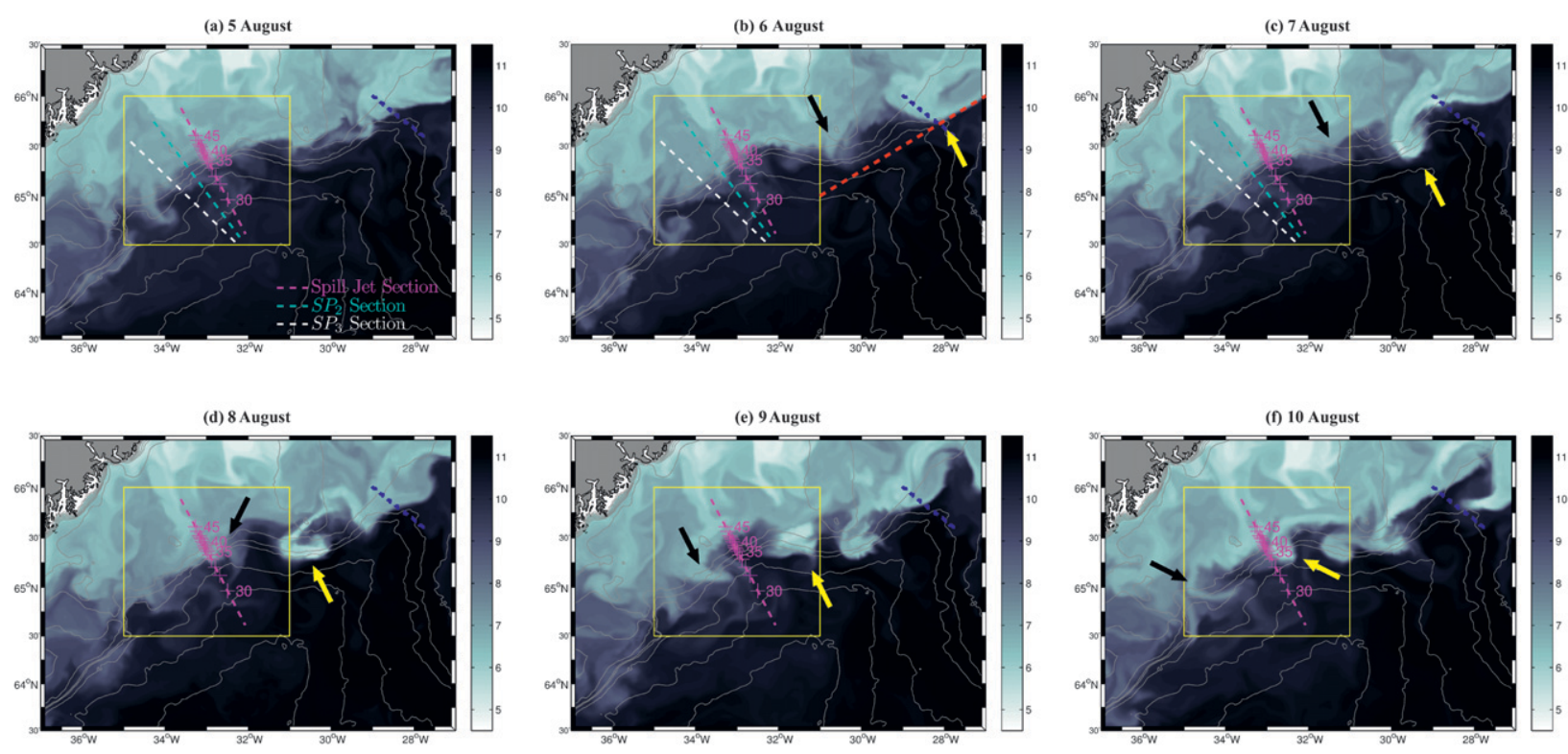

FIG. 3. Enlarged views of the model surface temperature $\left({ }^{\circ} \mathrm{C}\right)$ for the period 5-10 Aug. Germane sections are as in Fig. 1a, whereas the cyan and white dashed lines denote the sections $\mathrm{SP}_{2}$ and $\mathrm{SP}_{3}$, respectively. The numbers in magenta denote station positions for the 2003 Spill Jet section, occupied during 5-6 Aug. The yellow box denotes the close-up area discussed in section 3 . The evolution of two frontal meanders is followed with the black and yellow arrows. Gray lines indicate the same isobaths as in Fig. 1a.

against the western side of the sill at depths greater than $300 \mathrm{~m}$. Atlantic waters remain on the eastern side and are found to a depth of $400 \mathrm{~m}$. There is an isolated lens of Atlantic water at about $150 \mathrm{~m}$, which deforms the $\theta=$ $2^{\circ} \mathrm{C}$ isotherm in a pattern similar to the one shown in Macrander et al. (2007).

Figure 5 shows dense domes in the section along the thalweg of the Denmark Strait saddle (red line in Figs. 1a, 3b) on 6 August. The section corresponds to that shown in Fig. 5 of Käse et al. (2003). As in Käse et al. (2003), the dense domes move down the slope in contact with the sea floor, are $30-50 \mathrm{~km}$ in diameter, and are spaced 70 $100 \mathrm{~km}$ apart. The two dense deep domes in Fig. 5 correspond to the locations of the two surface cyclones in Fig. 3b (black and yellow arrows, respectively).

The domes are the main cause of the high-frequency variability of the DSO transport. They propagate to the Spill Jet section, so it is important to show that the model has a realistic DSO transport. To compare with the Ross (1977) mooring observations, the model DSO transport is calculated at the Denmark Strait south (DSS) section (blue line in Fig. 1a). Ross considered waters colder than $\theta=2^{\circ} \mathrm{C}$ and observed peaks lasting $1-2$ days separated by minima of 2-3 days (see also Fig. 7 of Bruce 1995 and Fig. 2 of Haine 2010). His month-long observations in August and September 1973 yield a mean equatorward transport of $2.8 \pm 1.5 \mathrm{~Sv}$. Figure 6 shows the model transports at the DSS section for $\theta \leq 2^{\circ} \mathrm{C}$ waters (blue line) and for $\sigma_{\theta} \geq 27.80 \mathrm{~kg} \mathrm{~m}^{-3}$ waters (black line). The two estimates show the same trend, even though the $\theta \leq$ $2^{\circ} \mathrm{C}$ cutoff is more restrictive and yields lower transport values. The model DSO fluctuations are consistent with the observations, and the model transport to the south for the entire period is $2.0 \pm 1.5 \mathrm{~Sv}$ for $\theta \leq 2^{\circ} \mathrm{C}$ and 2.9 $\pm 1.7 \mathrm{~Sv}$ for $\sigma_{\theta} \geq 27.80 \mathrm{~kg} \mathrm{~m}^{-3}$. Note that both DSO transports reach a peak on 6 August (labeled C in Fig. 6), which is consistent with the presence at the DSS section of the surface cyclone in Fig. 3b (yellow arrow) and the dense bolus centered at $180 \mathrm{~km}$ and $650 \mathrm{~m}$ in Fig. 5 .

\section{c. Spill Jet}

\section{1) OBSERVATIONS}

The model fields are now compared to the observations taken during summer 2003 at the Spill Jet section. The location is the same as the summer 2001 hydrographic survey that led to the discovery of the Spill Jet (refer to PTF05 for the 2001 fields). The 2003 survey shows a similar temperature field to that of 2001 (Fig. 7a). The cold waters of the East Greenland Current and the warm retroflected Irminger water form a front located between stations 43 and 44 . The data also show relatively dense $\left(\sigma_{\theta}>27.70 \mathrm{~kg} \mathrm{~m}^{-3}\right)$ and ventilated (dissolved oxygen concentration $C_{\mathrm{O}_{2}}>6.4 \mathrm{mll}^{-1}$ ) waters at the bottom of the shelf, whereas newly ventilated DSO waters $\left(\sigma_{\theta} \geq\right.$ $27.80 \mathrm{~kg} \mathrm{~m}^{-3}$ ) are banked against the continental slope deeper than $1200 \mathrm{~m}$ (Fig. 7b). The Spill Jet is present in 2003 on the outer shelf and upper slope as a bottom-intensified 

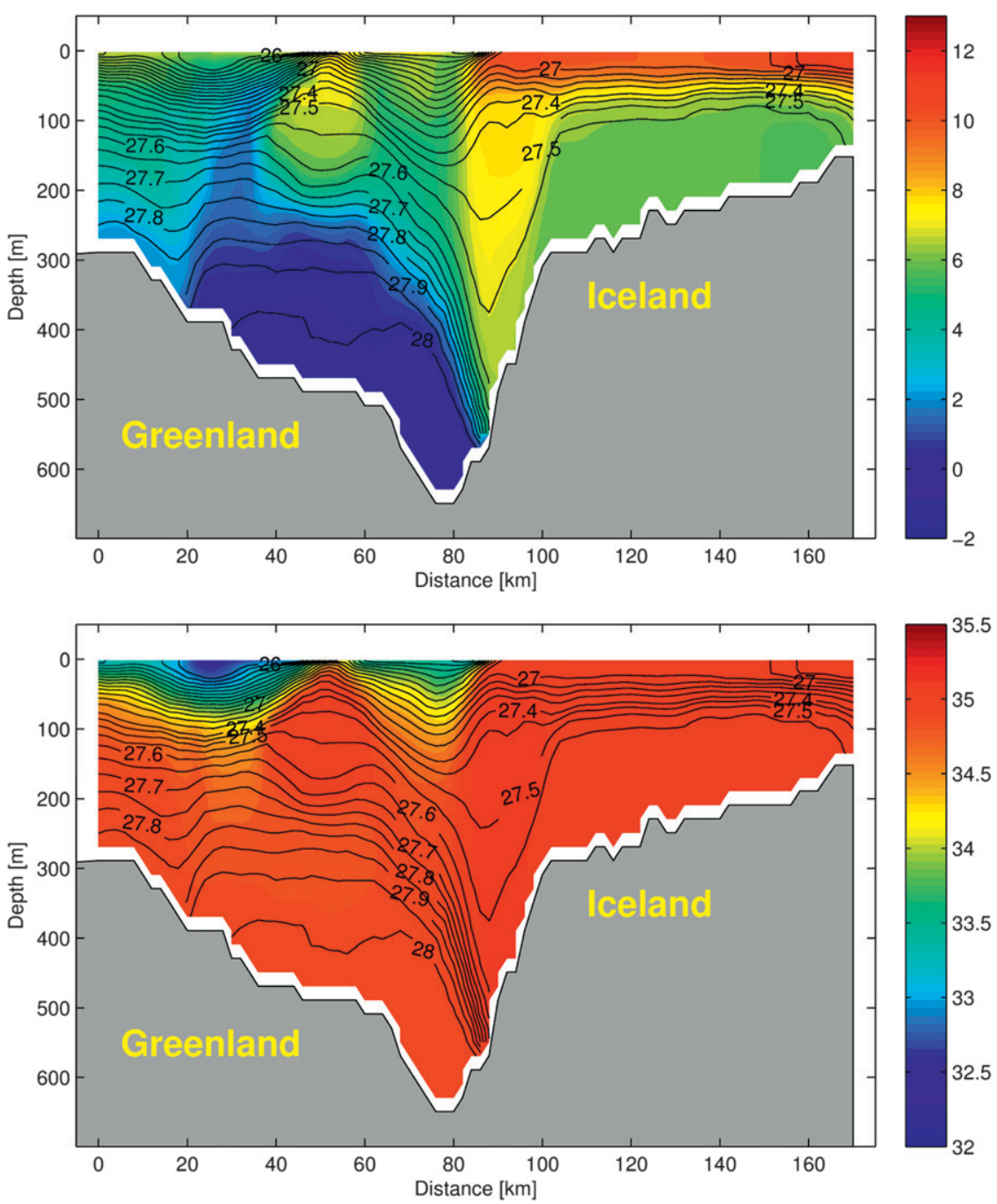

FIG. 4. Vertical section for model (top) potential temperature $\left({ }^{\circ} \mathrm{C}\right.$ ) and (bottom) salinity fields for 6 Aug at the Denmark Strait sill (green line in Fig. 1a). Black lines indicate potential density contours $\left(\mathrm{kg} \mathrm{m}^{-3}\right)$. The section is as in Fig. 1 of Macrander et al. (2007).

flow inshore of the Irminger Current (Fig. 7c, shoreward of the 700-m isobath). Seaward of the Irminger Current is a velocity minimum (in 1000-m water depth), and seaward of that is the DSO core (centered at $1400 \mathrm{~m}$ ).

Some differences with the 2001 observed fields are also evident. There is a clear increase in the upper-layer salinity field of about 0.3 (Fig. 7a), which is consistent with Sutherland and Pickart (2008), who showed that 2003 was an exceptionally salty year. Warm and salty Atlantic waters are observed to move shoreward in 2003 and occupy the area adjacent to the upper slope and the outer shelf (Fig. 7a). The same area is characterized in 2003 by an oxygen minimum $\left(C_{\mathrm{O}_{2}}>6.3 \mathrm{mll}^{-1}\right.$; Fig. $\left.7 \mathrm{~b}\right)$, whereas, in 2001, the region in the vicinity of the outer shelf and upper continental slope was characterized by higher dissolved oxygen concentration $\left(C_{\mathrm{O}_{2}}>6.4 \mathrm{ml}^{-1}\right.$; see Fig. 7b of PTF05). Furthermore, both relatively dense waters at the bottom of the shelf and the Spill Jet core are found farther inshore in 2003 than in 2001 (Fig. 7a). Another difference is that the offshore deepening of the isopycnals in the 2003 Spill Jet is less pronounced, and there is less lateral separation between the jet and the adjacent Irminger Current than in 2001. These differences suggest that the spilling of dense shelf waters down the slope is weaker in the 2003 snapshot than it was in 2001.

In 2001, the Spill Jet was clear as a near-bottom velocity maximum that extended over the shelf break and the upper continental slope. In 2003, the Spill Jet is at the shelf break but is less pronounced. For these reasons and anticipating the model results below, a specific definition 


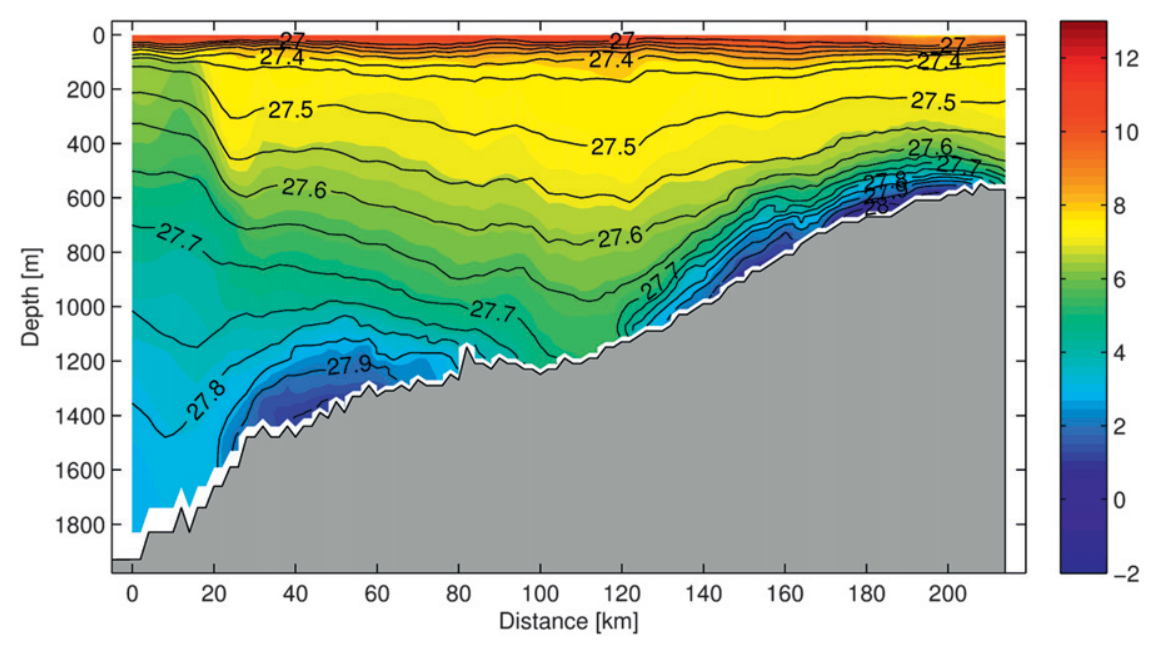

FIG. 5. Vertical section of model potential temperature $\left({ }^{\circ} \mathrm{C}\right)$ for 6 Aug at the section along the Denmark Strait thalweg descending into the Irminger Basin (red line in Fig. 1a). Black lines indicate potential density contours $\left(\mathrm{kg} \mathrm{m}^{-3}\right)$. The section is as in Fig. 5 of Käse et al. (2003).

is needed. Therefore, a high-speed core is here defined as a Spill Jet core if it

(i) consists of waters that can be traced back over the previous 2 days to the shelf in the area south of the Denmark Strait;

(ii) comprises waters with potential densities $\sigma_{\theta}<$ $27.80 \mathrm{~kg} \mathrm{~m}^{-3}$;

(iii) is characterized by Richardson numbers $\mathrm{Ri}<1$; and

(iv) is situated in the water column deeper than $200 \mathrm{~m}$ and less than $50 \mathrm{~km}$ seaward of the shelf break.

Criterion (i) ensures that the Spill Jet includes waters that have previously spilled from the shelf, criterion (ii) guarantees that these waters are light enough not to be considered DSO according to the definition by Dickson and Brown (1994), criterion (iii) ensures that they are characterized by enhanced vertical mixing as observed by PTF05, and criterion (iv) ensures that they are located in the modelaverage Spill Jet region (see green box in Fig. 14). Note that near-surface cyclones are excluded by (iii) because they are characterized by large Ri values (see Fig. 12d).

\section{2) MODEL FIELDS}

In this section, we show that dense waters spill off the Greenland shelf and then mix with and thereby modify the hydrographic characteristics of the waters along the slope. Spilling events are seen repeatedly throughout the 2-month simulation and in different locations southwest of Denmark Strait. There is significant variability from case to case, but in general there are two types of events. Examining the model fields between 5 and 10 August shows examples of each. The first type of event (called type I) is exemplified during 5-7 August, whereas the second (called type II) is exemplified during 8-10 August. We present detailed descriptions of these events in Figs. $8-12$, which show the model hydrography and circulation. Figure 13 is a schematic summary of the two types of events. The supplemental material includes a movie that illuminates the model results (available at the Journals Online Web site: http://dx.doi.org/10.1175/2010JPOD-10-05004.s1). Only the densest layers are displayed in the movie, and, as a result, type II events are more evident than type I events. It is also difficult to distinguish

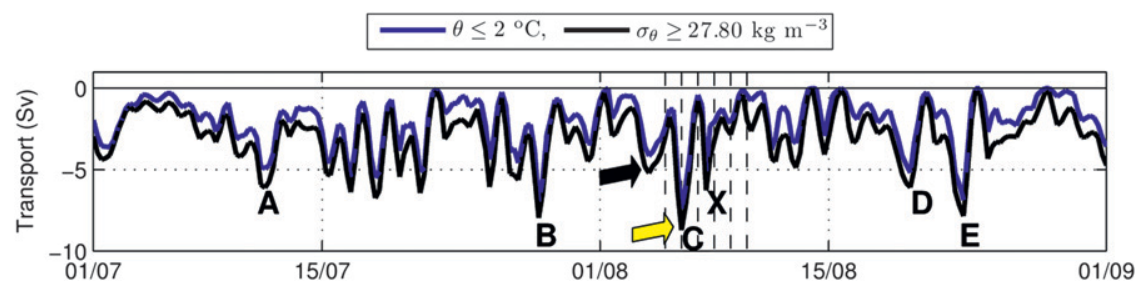

FIG. 6. Model DSO transport (Sv) for $\theta \leq 2^{\circ} \mathrm{C}$ (blue line) and for $\sigma_{\theta} \geq 27.80 \mathrm{~kg} \mathrm{~m}^{-3}$ (black line) at the DSS section (blue line in Fig. 1a). Dashed vertical lines indicate the days in the period 5-10 Aug. Letters identify some of the peak values in the transport. The two arrows indicate the times when the two disturbances shown in Fig. 3 occupy the DSS section. 
(a) Observations, Potential temperature and salinity, 5-6 August

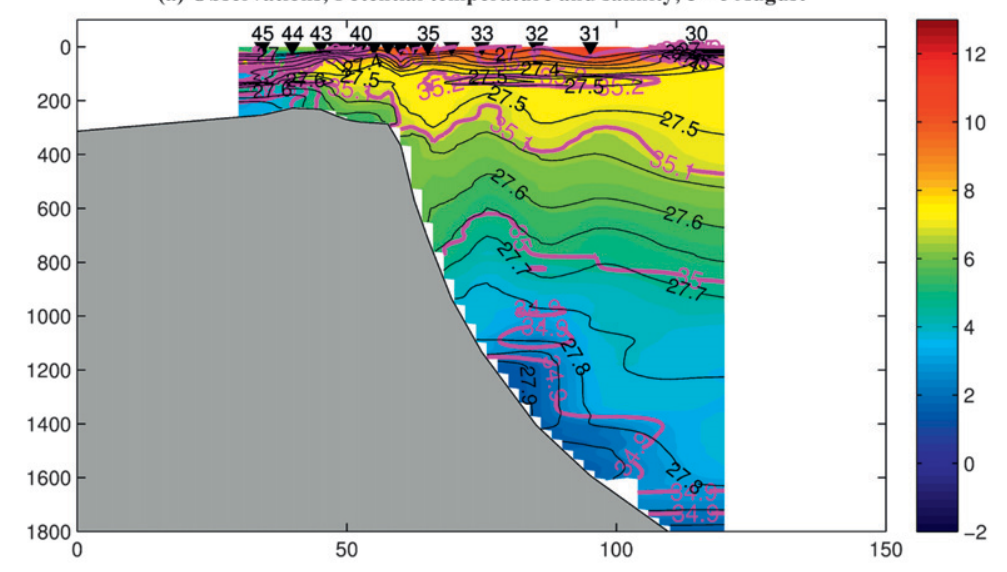

(b) Observations, Dissolved oxygen, 5-6 August

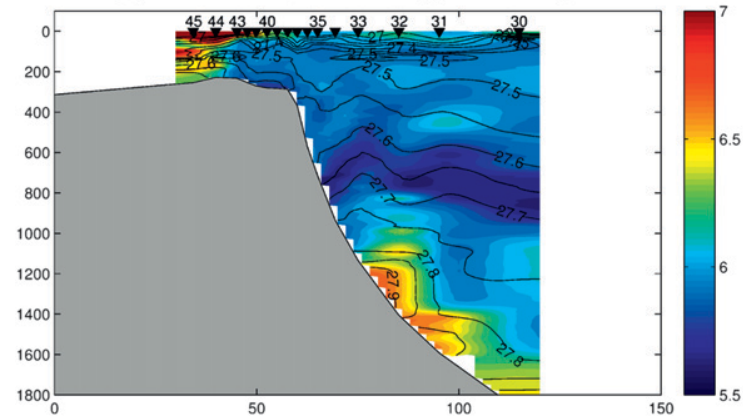

(c) Observations, Absolute geostrophic velocity, 5-6 August

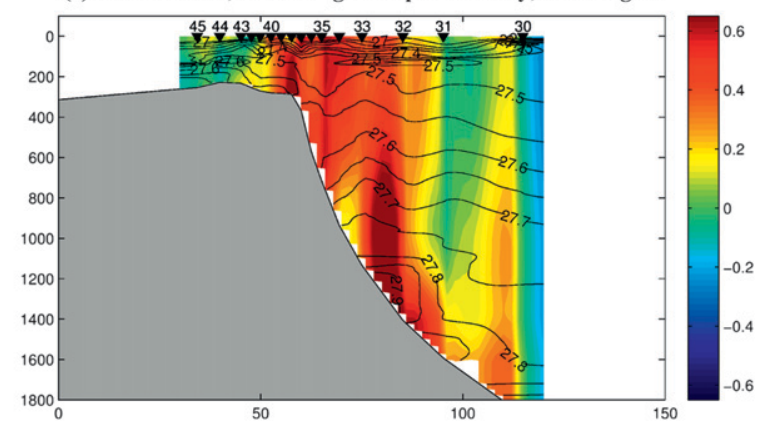

FIG. 7. Observations from the Spill Jet section (magenta line in Fig. 1a) during 5-6 Aug 2003. (a) Potential temperature ( ${ }^{\circ} \mathrm{C}$ ) and salinity (magenta thick contours); (b) dissolved oxygen ( $\mathrm{ml} \mathrm{l}^{-1}$ ); and (c) absolute geostrophic velocity ( $\mathrm{m} \mathrm{s}^{-1}$, where positive is equatorward). Black lines indicate potential density contours $\left(\mathrm{kg} \mathrm{m}^{-3}\right)$. The numbers indicate station locations.

type I lenses of water in the movie as they quickly merge with other dense structures at depth.

\section{(i) Type I event (5-7 August)}

We begin by considering the hydrographic fields at the Spill Jet section and compare them with the data. Figure 8 a shows the model potential temperature $\theta$ and density $\sigma_{\theta}$ at the Spill Jet section for 5 August, when the observations began. To facilitate the comparison with observations, station locations are also shown on these plots. As before, the model reproduces the general features of the observations in a realistic way. Some of the details are different: namely, (i) the model East Greenland-Irminger hydrographic front is located between stations 35 and 36, more offshore than in the data; (ii) the deepening of the model isopycnals in the Spill Jet area is more pronounced and resembles more the 2001 data; (iii) denser model shelf waters are located at the shelf break, closer to the slope; and (iv) in the deep model layer, the dense waters are lighter and the $\sigma_{\theta}=$ $27.85 \mathrm{~kg} \mathrm{~m}^{-3}$ isopycnal is missing. It will be clear shortly that these discrepancies are due to the high variability in the turbulent flow: no attempt has been made to match the phase of the model variations to the data.

Now compare the model fields at the Spill Jet section on 5 August to two sections farther downstream on the following 2 days (Figs. 8b,c). This provides a Lagrangian perspective of the event as the sections are spaced by the distance covered by the average speed of the EGC-IC front in one day $\left(0.27 \mathrm{~m} \mathrm{~s}^{-1}\right.$; Bruce 1995). On 5 August (Fig. 8a), the $\sigma_{\theta}=27.70 \mathrm{~kg} \mathrm{~m}^{-3}$ isopycnal bends down toward the seafloor at $900 \mathrm{~m}$ and is disconnected from the shelf break. At that time, the cross-stream velocity on the shelf is directed offshore (Fig. 9; discussed further below), and the relatively dense waters at the shelf break are starting to spill down the slope. Downward motion reaches speeds of $O(1) \mathrm{cm} \mathrm{s}^{-1}$ and is strongest at the shelf break and also near $1200 \mathrm{~m}$. As the spilling occurs, the relatively dense shelf waters sink and move downstream in the strong current running along the shelf break (Fig. 8d; also discussed further below). Over the next 2 days, the model fields downstream of the Spill Jet section evolve because of this spilling event. Figure $8 \mathrm{~b}$ shows the hydrography at the $\mathrm{SP}_{2}$ section (cyan line in Fig. 3; SP stands for spilling) on 6 August. The 
(a) Model $\theta$, Spill Jet section, 5 August

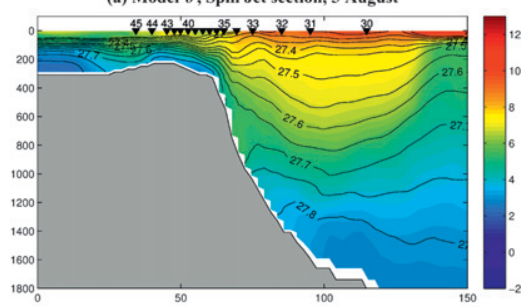

(d) Normal velocity, Spill Jet section, 5 August

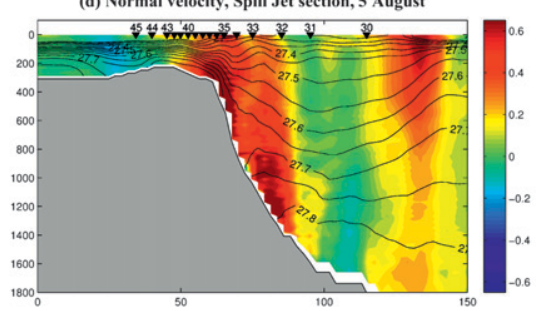

(b) Model $\theta, S P_{2}$ section, 6 August

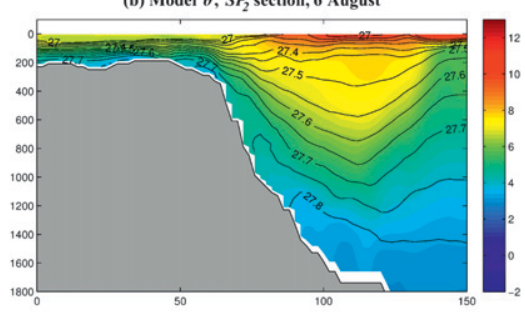

(e) Normal velocity, $S P_{2}$ section, 6 August

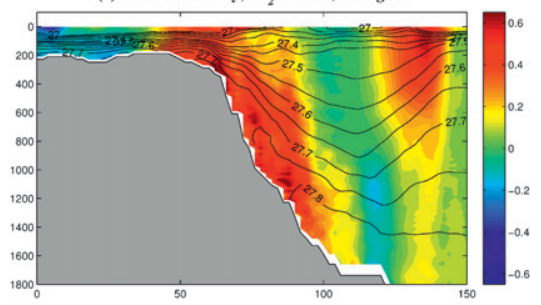

(c) Model $\theta, S P_{3}$ section, 7 August

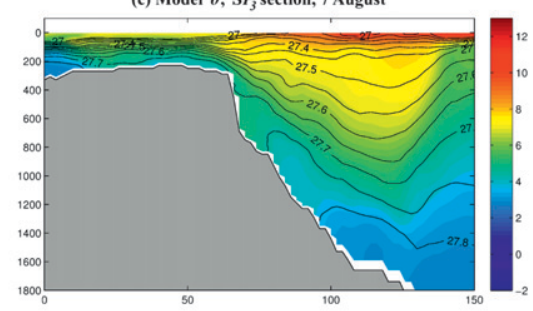

(f) Normal velocity, $\mathrm{SP}_{3}$ section, 7 August

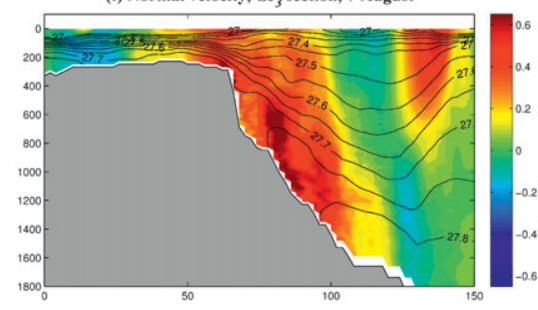

FIG. 8. Model vertical sections for (top) potential temperature $\theta\left({ }^{\circ} \mathrm{C}\right)$ and (bottom) normal horizontal velocity ( $\left.\mathrm{m} \mathrm{s}^{-1}\right)$ : (a), (d) 5 Aug at the Spill Jet section (magenta line in Fig. 3); (b),(e) 6 Aug at the $\mathrm{SP}_{2}$ section (cyan line in Fig. 3); and (c),(f) 7 Aug at the $\mathrm{SP}_{3}$ section (white line in Fig. 3). Positive speeds stand for equatorward flow. Black lines indicate potential density contours $\left(\mathrm{kg} \mathrm{m}^{-3}\right)$. Numbers indicate $5-6$ Aug station locations.

$\sigma_{\theta}=27.70 \mathrm{~kg} \mathrm{~m}^{-3}$ contour is now strongly tilted upward and directly connects with waters on the shelf, whereas the $\sigma_{\theta}=27.75 \mathrm{~kg} \mathrm{~m}^{-3}$ isopycnal is convoluted and encloses a dense anomaly near the slope at $900 \mathrm{~m}$. The hydrography on 7 August at the $\mathrm{SP}_{3}$ section (white line in Fig. 3) is similar, but the $\sigma_{\theta}=27.75 \mathrm{~kg} \mathrm{~m}^{-3}$ anomaly on the slope is larger (Fig. 8c). Note that, during this spilling sequence, the lateral position of the East GreenlandIrminger hydrographic front has not changed much (see also Figs. 3a-c).

The along-stream velocity is shown in Fig. 8 (bottom). On 5 August, at the Spill Jet section, the velocity field consists of three distinct cores exceeding $0.6 \mathrm{~m} \mathrm{~s}^{-1}$ (Fig. 8d). The first one is the Irminger Current, lying as a surfaceintensified flow where the isopycnals slope upward offshore. The other two cores are Spill Jet cores according to the definition given in section 3c(1). The first Spill Jet core is visible on 5 August across the shelf break (between station 34 and 38). This core is similar to that identified in the 2001 snapshot by PTF05. The jet is associated with enhanced downward motion as seen in Fig. $9 \mathrm{~b}$ and with Richardson numbers $\mathrm{Ri}<1$ (not shown).

The deeper Spill Jet core (between station 32 and 33, centered at about $1200 \mathrm{~m}$ ) is intriguing. The velocity field resembles the 2001 view given by PTF05 (cf. their Fig. 7), where they defined the lower jet to be the DSO. As in PTF05, the model lower jet in Fig. $8 \mathrm{~d}$ is lighter than traditional DSO water, however, because most of the jet has $\sigma_{\theta}<27.80 \mathrm{~kg} \mathrm{~m}^{-3}$. The lower jet coincides with strong downward vertical velocities (Fig. 9b) and with low Richardson numbers (not shown). Thus, it has the characteristics of the Spill Jet. A careful analysis of the model fields suggests that lower jet waters were previously spilled upstream at 1800 UTC 3 August, in the area just west of the Kangerdlugssuaq Trough (see Fig. 1a). In transit to the Spill Jet section, the lower jet waters descended the slope. Therefore, they have not spilled locally, but, given our definition, they qualify as Spill Jet water.

Figures 8e,f follow the fate of the two jets in the subsequent 2 days at sections $\mathrm{SP}_{2}$ and $\mathrm{SP}_{3}$, respectively. On 6 August, at $\mathrm{SP}_{2}$, a broader and weaker high-speed area is centered at about $700 \mathrm{~m}$. We believe that this feature results from interaction between the two jet cores. Waters with $\sigma_{\theta} \sim 27.75 \mathrm{~kg} \mathrm{~m}^{-3}$ spill at the Spill Jet section on 5 August. Some of them mix with the adjacent lighter $\left(\sigma_{\theta} \sim 27.65 \mathrm{~kg} \mathrm{~m}^{-3}\right)$ waters forcing the $\sigma_{\theta}=$ $27.70 \mathrm{~kg} \mathrm{~m}^{-3}$ line to tilt upward at $\mathrm{SP}_{2}$ a day later. The remaining waters merge with the lower jet core and form the $\sigma_{\theta}=27.75 \mathrm{~kg} \mathrm{~m}^{-3}$ contour anomaly at about $900 \mathrm{~m}$. On 7 August, at section $\mathrm{SP}_{3}$, the velocity maximum descends deeper than $1000 \mathrm{~m}$ and the interaction between the upper and lower jets is more evident. During this sequence, the vertical displacement of the $\sigma_{\theta}=27.80 \mathrm{~kg} \mathrm{~m}^{-3}$ isopycnal is small compared to those experienced by the $\sigma_{\theta}=27.70 \mathrm{~kg} \mathrm{~m}^{-3}$ and $\sigma_{\theta}=27.75 \mathrm{~kg} \mathrm{~m}^{-3}$ contours.

The model fields on 5-7 August exemplify a type of spilling event we call type I. In events of this type, a lens of dense water detaches from the outer shelf and moves downslope. It then mixes with lighter ambient waters during the descent, and, at times, it interacts with other dense structures passing through the section that have spilled from the shelf earlier and upstream. The surface 
(a) 5 August, surface horizontal velocity and temperature

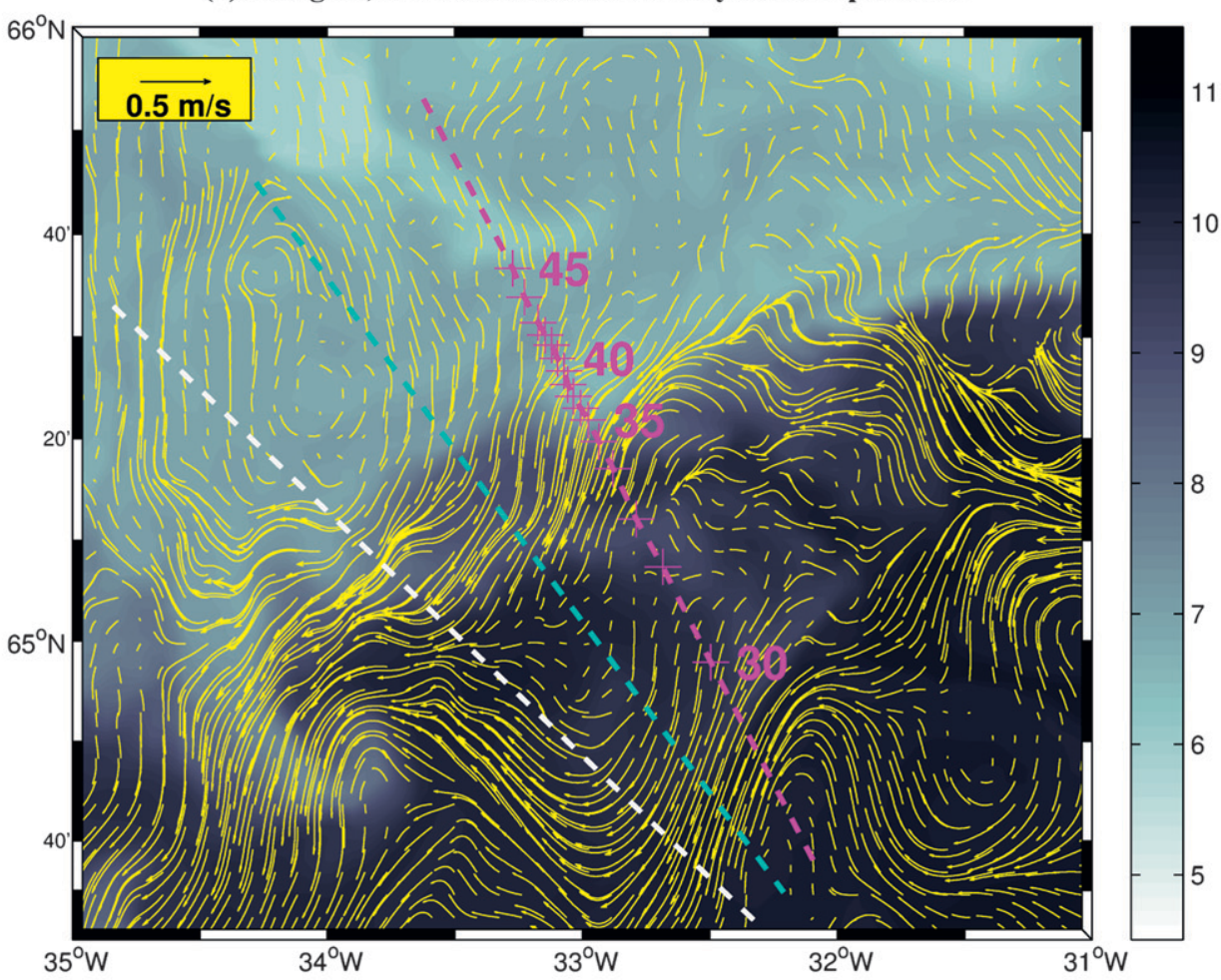

(b) Lateral circulation at the Spill Jet section

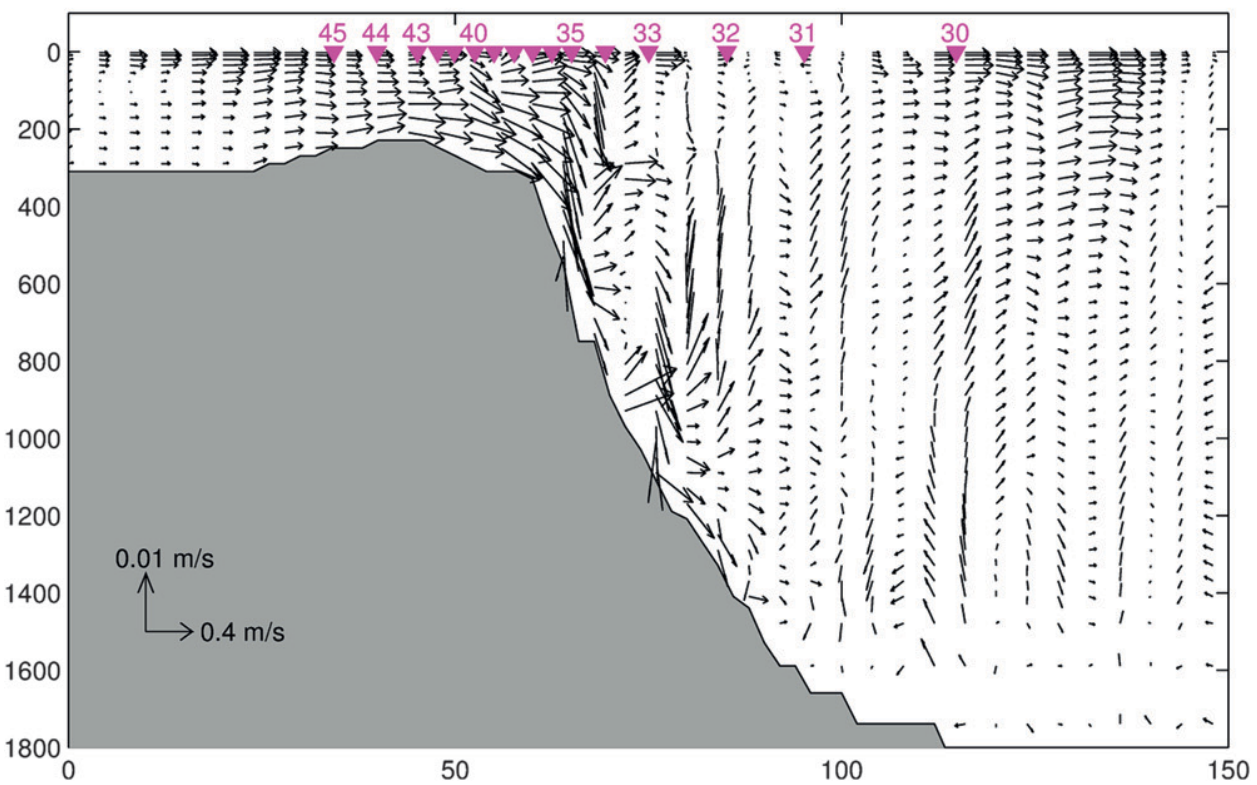

FIG. 9. Flow on 5 Aug: (a) enlarged view of the model surface temperature $\left({ }^{\circ} \mathrm{C}\right)$ and horizontal velocity in the area enclosed in the yellow box in Fig. 3. For clarity, horizontal velocity arrows are plotted every third grid point. (b) Model cross-stream lateral circulation at the Spill Jet section. For clarity, lateral velocity arrows are plotted every second grid point. Station positions for the 2003 Spill Jet section are shown in magenta. The $\mathrm{SP}_{2}$ section is in cyan, and the $\mathrm{SP}_{3}$ section is in white. 

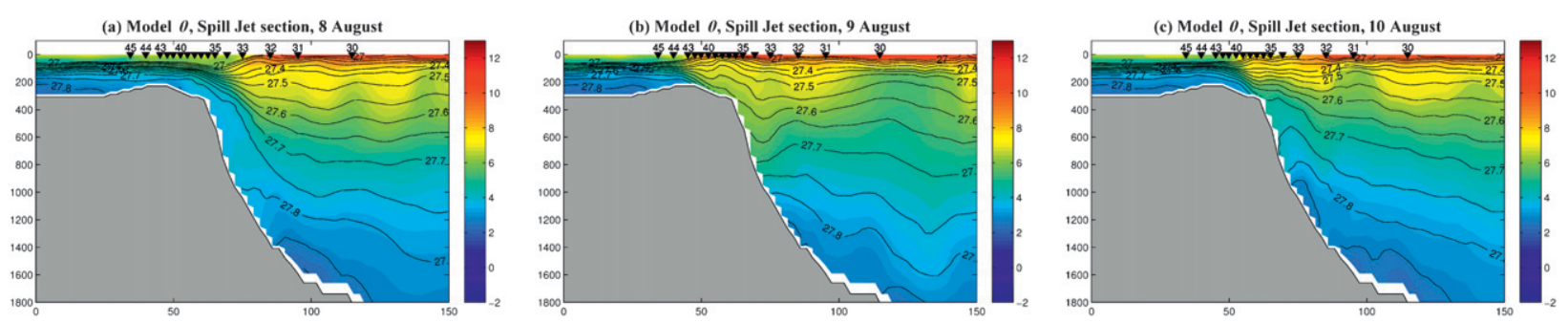

FIG. 10. Model vertical sections for potential temperature $\theta\left({ }^{\circ} \mathrm{C}\right)$ at the Spill Jet section (magenta line in Fig. 1a) during (a)-(c) 8-10 Aug. Black lines indicate potential density contours $\left(\mathrm{kg} \mathrm{m}^{-3}\right)$. Numbers indicate 5-6 Aug station locations.

front remains at the shelf break. This sequence is indicated schematically in the Fig. 13 (top).

The hydrography at the Spill Jet section evolves similarly to the above-described Lagrangian view during 5-7 August (not shown). In particular, the $\sigma_{\theta}=27.70 \mathrm{~kg} \mathrm{~m}^{-3}$ contour also tilts upward and the dense $\sigma_{\theta}=27.75 \mathrm{~kg} \mathrm{~m}^{-3}$ anomaly can be found near the slope, this time at $1000 \mathrm{~m}$. This result also suggests that dense waters spill over the shelf upstream of the Spill Jet section and are advected downstream through the section.

\section{(ii) Type II event (8-10 August)}

We now consider the second type of spilling event revealed by the model, using an Eulerian viewpoint. The model hydrography at the Spill Jet section for 8-10 August is shown in Fig. 10. On 8 August, the front is farther offshore, between stations 32 and 33. At that time, dense waters with $\sigma_{\theta} \geq 27.85 \mathrm{~kg} \mathrm{~m}^{-3}$ are present in the deeper part of the section. The appearance of dense waters, together with the frontal shift, coincides with the passage of the surface cyclone through the Spill Jet section (see Fig. 3d). Dense waters located on the shelf and along the slope are in contact. The layer with $27.75 \mathrm{~kg} \mathrm{~m}^{-3} \leq \sigma_{\theta} \leq 27.80 \mathrm{~kg} \mathrm{~m}^{-3}$ has thickened, and now even the $\sigma_{\theta}=27.75 \mathrm{~kg} \mathrm{~m}^{-3}$ isopycnal tilts upward to the shelf.

On 9 August, the East Greenland-Irminger hydrographic front lies farther inshore, as in the observations. The shift is due to the passage of the surface meander, which is followed by warmer waters (see Fig. 3e). The contact between dense shelf and slope waters is interrupted again. The isopycnal slope in the shelfbreak area is reduced, and $\sigma_{\theta}=27.70 \mathrm{~kg} \mathrm{~m}^{-3}$ bends back down toward the bottom. With the exception of the $\sigma_{\theta} \geq 27.85 \mathrm{~kg} \mathrm{~m}^{-3}$ waters, which are barely present, the model fields for early 9 August are similar to the data.

Later in the day, on 9 August and into 10 August, the second surface cyclone passes by the Spill Jet section (see Fig. 3f). Its instantaneous speed is $0.62 \mathrm{~m} \mathrm{~s}^{-1}$, in agreement with Krauss (1996), who indicated that cyclones move faster than the surrounding flow by $0.1-0.3 \mathrm{~m} \mathrm{~s}^{-1}$. The cross-stream velocity associated with the leading edge of this eddy is directed offshore and induces spilling (Figs. 11a,b, on 1800 UTC 9 August). The shelf and slope waters are not yet fully connected, but the $\sigma_{\theta}=27.70 \mathrm{~kg} \mathrm{~m}^{-3}$ contour tilts upward and the $\sigma_{\theta} \geq 27.85 \mathrm{~kg} \mathrm{~m}^{-3}$ waters appear again at depth. The downward motion at the shelf break is again about $1 \mathrm{~cm} \mathrm{~s}^{-1}$ but peaks above the seafloor at $1000 \mathrm{~m}$.

The changes in the along-stream velocity field at the Spill Jet section during 8-10 August indicate that the presence of a DSO bolus strongly influenced the circulation. On 8 August, a deep jet lies along the slope, centered at about $1600 \mathrm{~m}$ (Fig. 12a). This jet coincides with the dense $\left(\sigma_{\theta} \geq 27.85 \mathrm{~kg} \mathrm{~m}^{-3}\right)$ deep bolus passing through the section. A surface cyclone can also be identified in the upper layers, where Ri values are high near the shelf break. A weaker Spill Jet core lies along the slope between the surface cyclone and the dense bolus, centered at about $800 \mathrm{~m}$, between stations 32 and 35. This core is due to waters drawn off the shelf earlier by the leading edge of the surface cyclone. The lower edge of this Spill Jet extends to the $\sigma_{\theta}=27.80 \mathrm{~kg} \mathrm{~m}^{-3}$ isopycnal at about $1100 \mathrm{~m}$, but it remains distinct from the dense bolus by the velocity minimum located at about $1400 \mathrm{~m}$. The upper edge of the Spill Jet is at the shelf break, where low Ri values occur (Fig. 12d). The upper edge is less distinct in the velocity field, because the weaker jet overlaps with the high speeds of the surface cyclone.

On 9 August, warm waters meander onshore and the flow has a strong barotropic component (Fig. 12b). A similar barotropic velocity field was observed in 2004 at the same location, when Atlantic waters were also intruding on the shelf (cf. Fig. 6 of Sutherland and Pickart 2008). The dense $\sigma_{\theta} \geq 27.85 \mathrm{~kg} \mathrm{~m}^{-3}$ bolus is now deeper while an intense surface jet (peak speed of $0.9 \mathrm{~m} \mathrm{~s}^{-1}$ ) lies above the upper slope. The density and Ri fields indicate the presence of a Spill Jet core in the upper slope (Fig. 12e), but not shallower than the shelf break.

On 10 August, the front is moving back offshore, and the isopycnals in the vicinity of the upper slope are tilting again. An upper core is found along the slope between stations 32 and 35, where low Ri values are seen (Fig. 12f). Inspection of the model fields shows that this 
(a) 1800 UTC 9 August, surface horizontal velocity and temperature

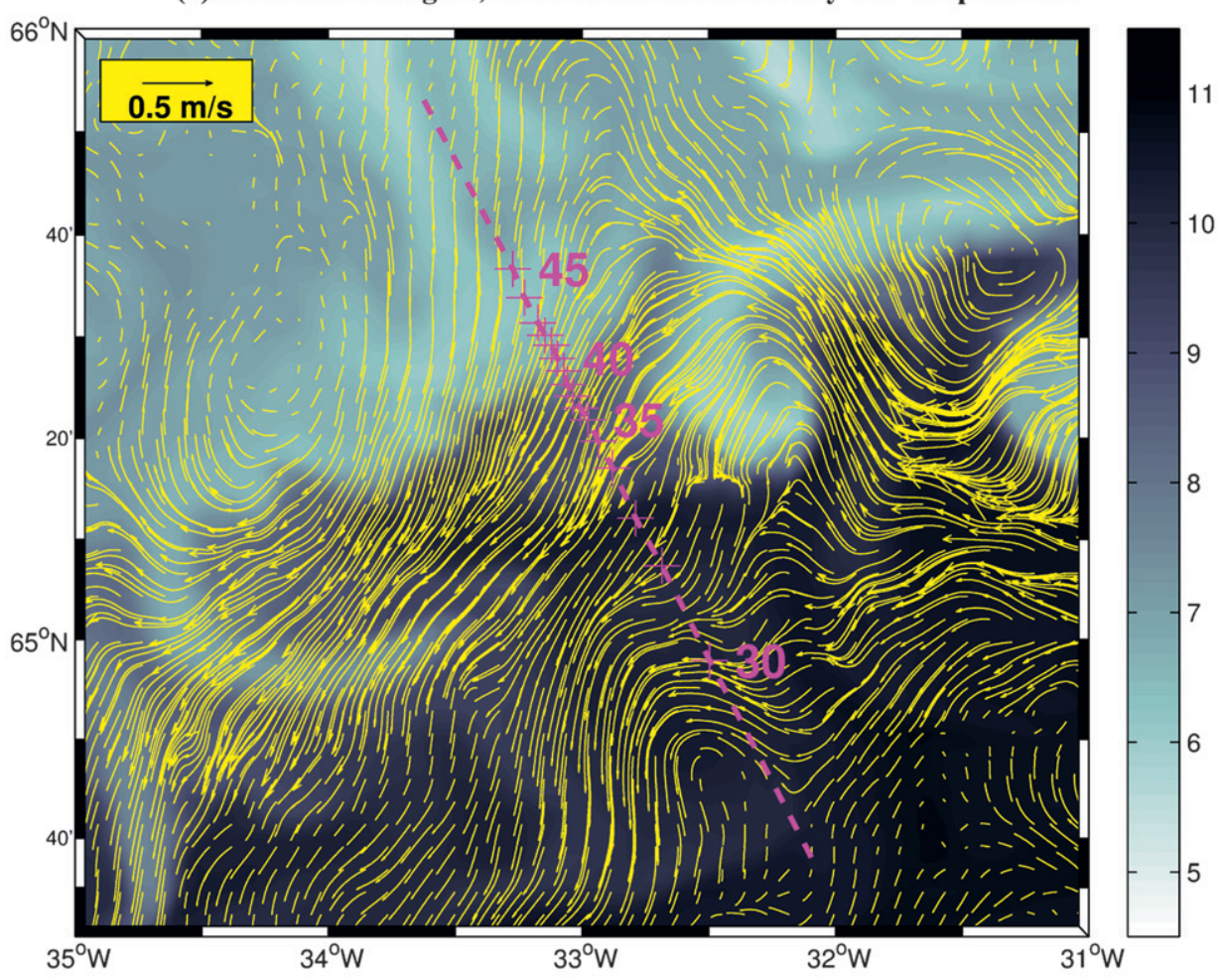

(b) Lateral circulation at the Spill Jet section

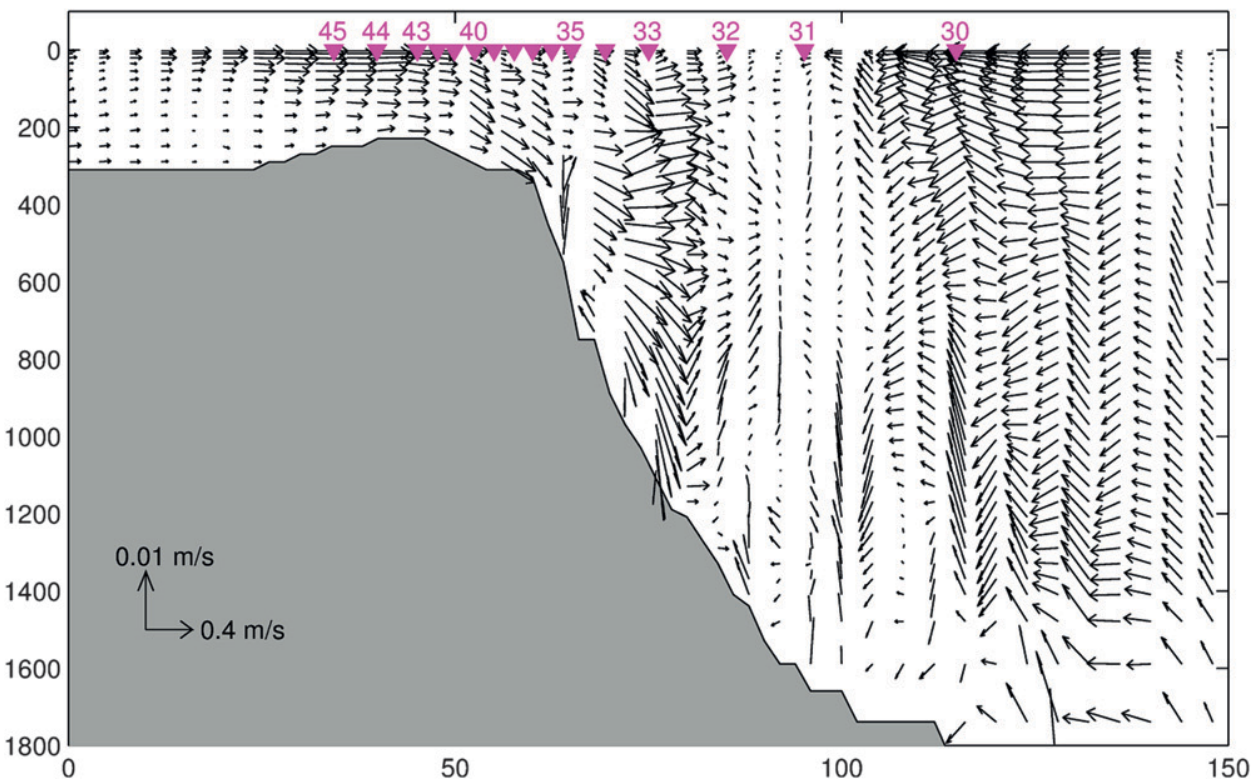

FIG. 11. As in Fig. 9, but for 1800 UTC 9 Aug.

is a Spill Jet core, because it comprises dense shelf waters that have been spilling from the Kangerdlugssuaq Trough. The Spill Jet core is more distinct from the strong near-surface flow than in the previous 2 days, and it remains distinct from the deep DSO bolus jet because of the velocity minimum at about $1400 \mathrm{~m}$. The DSO bolus consists of dense waters coming from the sill. Notice that the Spill Jet core represents an exception to our definition, because it includes dense $\sigma_{\theta} \geq 27.85 \mathrm{~kg} \mathrm{~m}^{-3}$ waters that are not DSO. 
(a) Normal velocity, Spill Jet section, 8 August

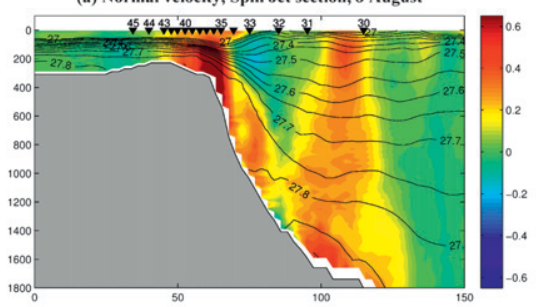

(d) $R i$, Spill Jet section, 8 August

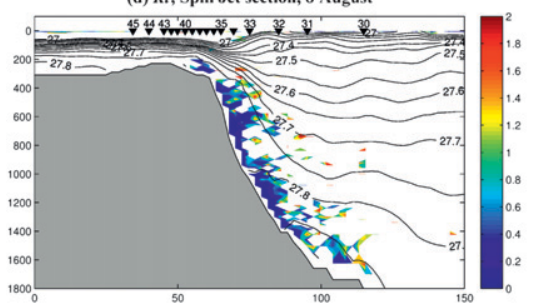

(b) Normal velocity, Spill Jet section, 9 August

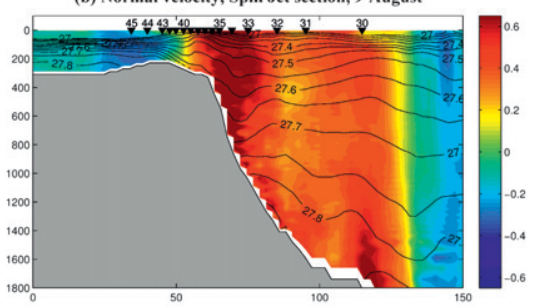

(e) $R i$, Spill Jet section, 9 August

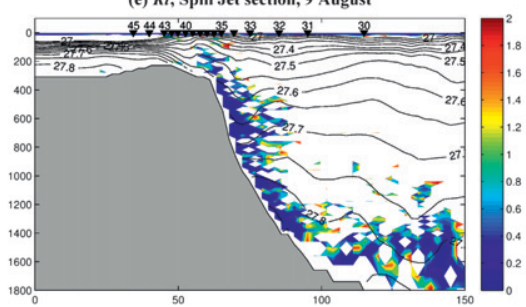

(c) Normal velocity, Spill Jet section, 10 August

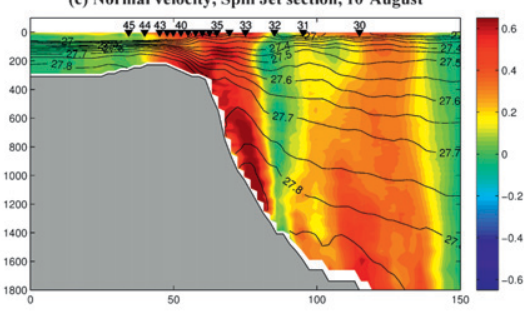

(f) $R i$, Spill Jet section, 10 August

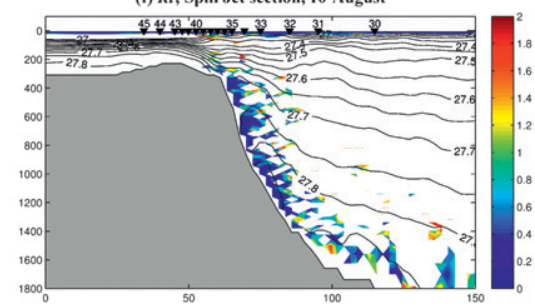

FIG. 12. Vertical sections for (top) the model normal horizontal velocity ( $\mathrm{m} \mathrm{s}^{-1}$ ) and (bottom) Richardson number Ri at the Spill Jet section (magenta line in Fig. 1a) for (left to right) 8-10 Aug. Positive speeds stand for equatorward flow and Richardson numbers Ri $\geq 2$ have been masked. Black lines indicate potential density contours $\left(\mathrm{kg} \mathrm{m}^{-3}\right)$. Numbers indicate 5-6 Aug station locations.

The model fields on 8-10 August exemplify the second type of spilling event, which we refer to as type II (Fig. 13, bottom). In events of this type, the spilling is associated with the passage of cold surface cyclones, which are linked to deep DSO pulses. This kind of spilling event involves the propagation of the dense DSO domes. Dense shelf water is drawn off by the leading edge of the cyclonic feature and starts to sink. (a) Type I

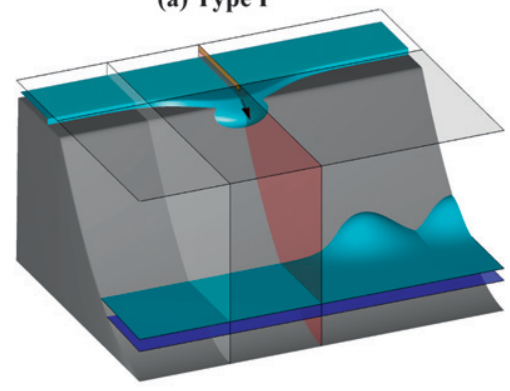

(d) Type II

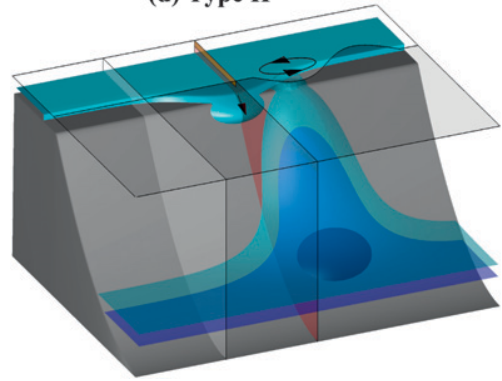

(b) Type I

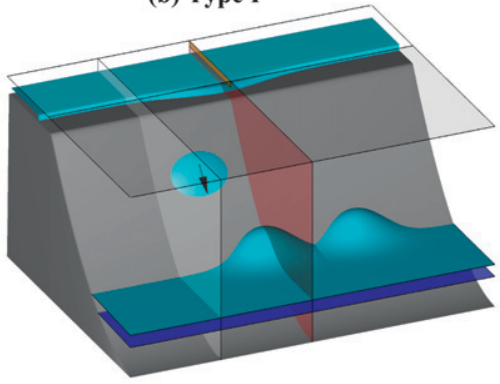

(e) Type II

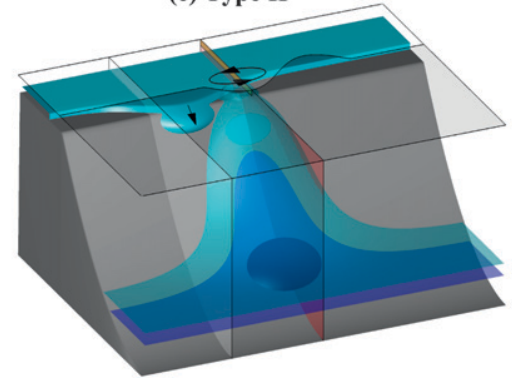

(c) Type I

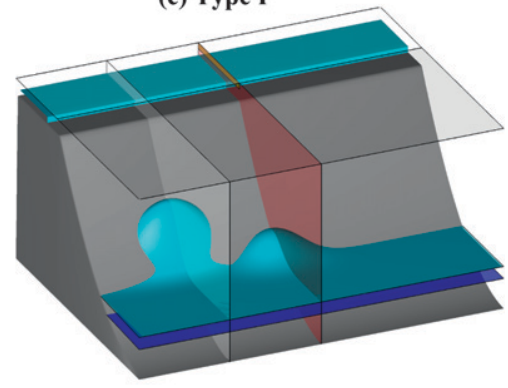

(f) Type II

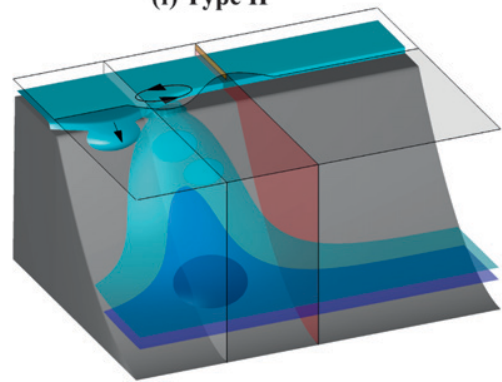

FIG. 13. Schematic representation of the two different types of spilling events. (top) In the first case (type I), the spilling is due to a lens of dense water descending the slope, which may interact with other dense structures at depth that have recently spilled from the shelf upstream. (bottom) In the second case (type II), the spilling is caused by the passage of a cyclonic feature, linked to DSO boluses, that draws dense waters off the shelf (see text). The magenta section indicates an idealized Spill Jet section, whereas the yellow top stripe stands for the idealized position of the surface front. The white section indicates an idealized section downstream of the Spill Jet section. The cyan and violet surfaces represent the idealized positions of the $\sigma_{\theta}=27.75$ and $\sigma_{\theta}=27.80 \mathrm{~kg} \mathrm{~m}^{-3}$ isopycnals, respectively. The dark blue disks at depth are indicative of $\sigma_{\theta} \geq 27.85 \mathrm{~kg} \mathrm{~m}^{-3}$ waters and denote the idealized DSO dense domes. 


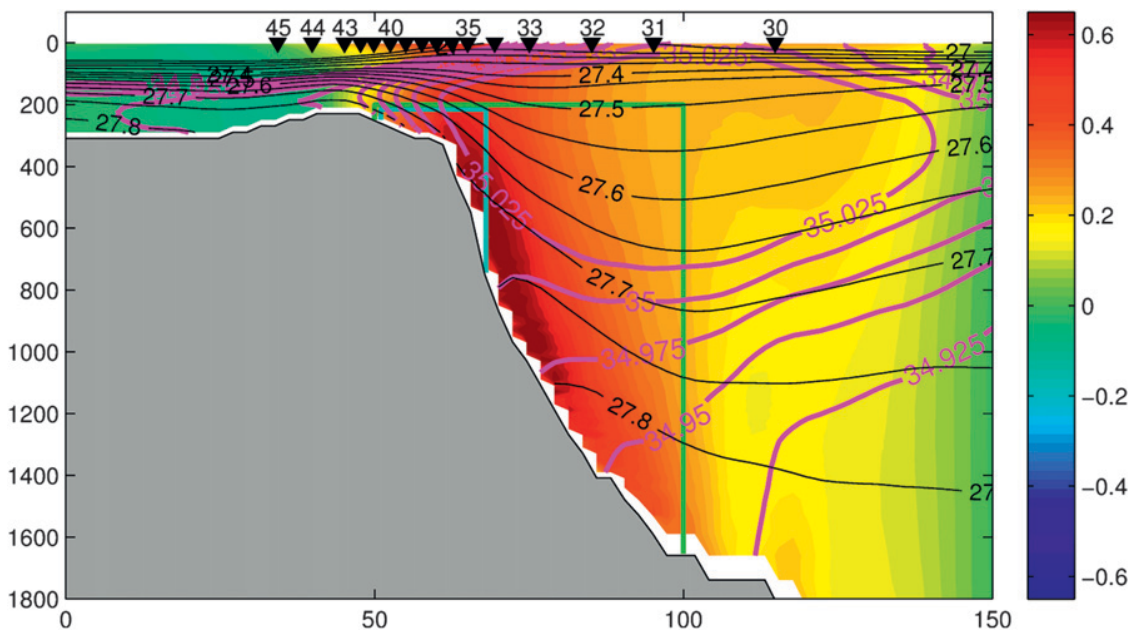

FIG. 14. Time-averaged vertical section of the model normal velocity $\left(\mathrm{m} \mathrm{s}^{-1}\right)$, at the Spill Jet section (magenta line in Fig. 1a). Positive speeds denote equatorward flow. Black lines indicate potential density contours $\left(\mathrm{kg} \mathrm{m}^{-3}\right)$, whereas thick magenta lines are salinity contours. The cyan and green rectangles are the region used to calculate volume transport estimates for the Spill Jet (see text). The green rectangle overlies the cyan rectangle. For clarity, two edges of the latter are slightly displaced in the figure. Numbers indicate 5-6 Aug station locations.

The spilled water mixes with waters of the cyclone that have similar densities and are traveling equatorward along the slope.

\section{3) TRANSPORTS}

The Spill Jet is present in all the velocity snapshots of Figs. 8 and 12. It is also present during the entire simulation period and is therefore evident in the section of time-averaged velocity over the two months shown in Fig. 14. The inner high-speed core of the average Spill Jet extends from the shelf break to about $1200 \mathrm{~m}$, or roughly the $\sigma_{\theta}=27.80 \mathrm{~kg} \mathrm{~m}^{-3}$ isopycnal.

To calculate the Spill Jet volume transport, the jet needs to be separated from the DSO. So far, we have used the $\sigma_{\theta}=27.80 \mathrm{~kg} \mathrm{~m}^{-3}$ isopycnal as the upper limit for the DSO. This value is commonly chosen to identify the overflow interface (e.g., Dickson and Brown 1994). Note, however, that this separation is somewhat arbitrary, and distinguishing between Spill Jet water and DSO is hard when the former velocity core contains denser waters, as seen in Fig. 12c, for example.

The estimated volume transport for the DSO $\sigma_{\theta} \geq$ $27.80 \mathrm{~kg} \mathrm{~m}^{-3}$ waters considering the entire Spill Jet section is shown in Fig. 15a. Only layers deeper than $450 \mathrm{~m}$ are used for this calculation to exclude waters with the same density that can be occasionally found on the shelf. The time series in Fig. 15a shows peaks similar to those observed upstream, at the Denmark Strait south section (cf. Fig. 6). For example, peaks on the DSS section on 11 July (peak A), 28 July (peak B), and 6 August (peak
C) are observed downstream on 15 July, 1 August, and 10 August, respectively. Inspection of a three-dimensional animation of isopycnic surfaces shows that the peaks correspond to the passage of the deep boluses through the section. The evolution of peak $\mathrm{C}$ is also consistent with the sea surface temperature snapshots in Fig. 3. The two DSO transport series in Figs. 6 and 15a reach maximum correlation $\left(r=0.50\right.$, significance level $\left.p<10^{-15}\right)$ when offset by 3.75 days. The average DSO transport in Fig. 15a is $-6.1 \pm 2.8 \mathrm{~Sv}$, in line with the $-6 \mathrm{~Sv}$ of PTF05 and the $-5.2 \mathrm{~Sv}$ of Dickson and Brown (1994) at this location. The twofold increase in DSO transport from 2.9 Sv at the DSS section is due to entrainment and mixing with the ambient Irminger Sea waters.

An estimate for the volume transport of the Spill Jet is not trivial to obtain. PTF05 considered waters confined in a region across the shelf break (see their Fig. 4 and the cyan box in Fig. 14). Although suitable for the 2001 synoptic snapshot, this region covers only part of the model-average Spill Jet (see Fig. 14). Nevertheless, an estimate (called $Q_{1}$ ) using this smaller area provides a useful comparison and is shown in Fig. 15b. The transport curve shows peaks when strong southward jets are observed at the shelf break (as between 8 and 9 August) and minima when high velocities are not located within the box (as on 7 August). The average value is $-1.8 \pm 0.6 \mathrm{~Sv}$, in line with the $-1.9-\mathrm{Sv}$ synoptic Spill Jet estimate measured in 2001 by PTF05. Maximum synoptic values in the model exceed $-3 \mathrm{~Sv}$. The $Q_{1}$ time series also shows peaks similar in character to those in 
(a) DSO waters at the Spill Jet section

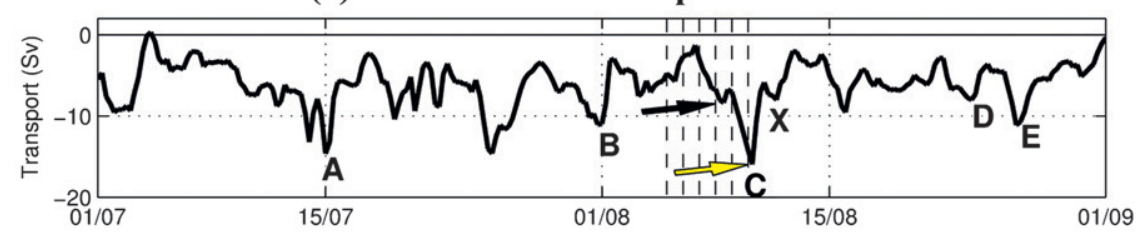

(b) $Q_{1}$ estimate; cyan box

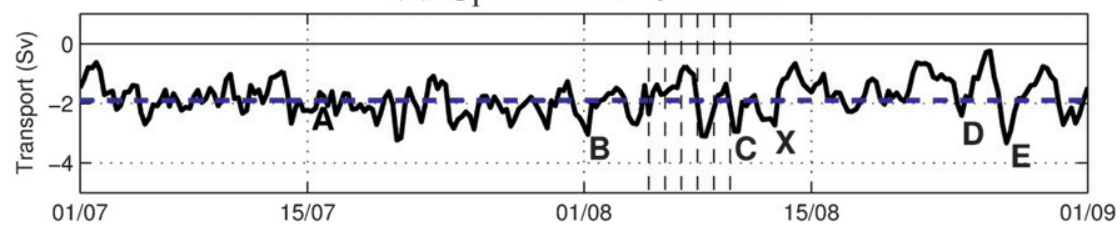

(c) $Q_{2}$ estimate; green box

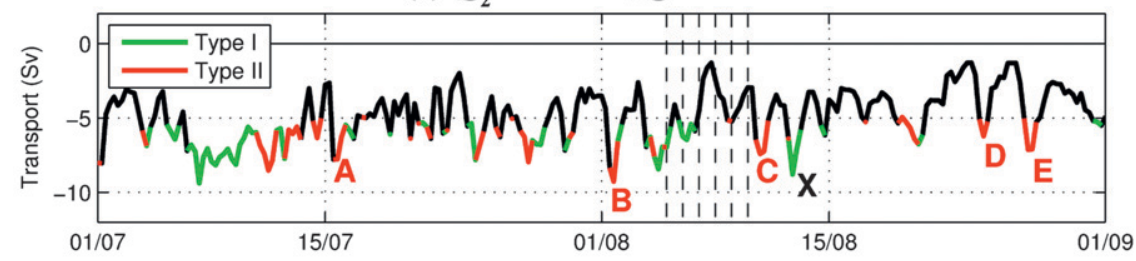

(d) Averaged alongshore wind stress component

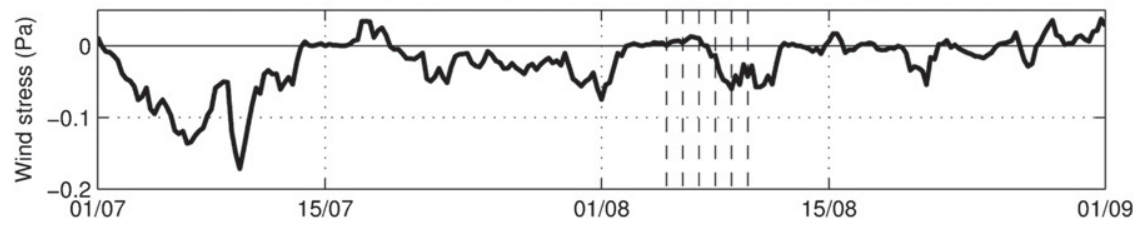

FIG. 15. (a)-(c) Model transports (Sv) - (a) DSO waters, (b) $Q_{1}$ estimate, and (c) $Q_{2}$ estimateand (d) spatially averaged alongshore component of the wind stress ( $\mathrm{Pa}$; negative stress indicates northeasterly winds) at the Spill Jet section. Dashed vertical lines indicate the days in the period 5-10 Aug. See text for definitions of the Spill Jet transport estimates. Letters identify some of the peak values in the transports. (a) The two arrows indicate the times when the two disturbances shown in Fig. 3 occupy the Spill Jet section. (b) The blue dashed line indicates the observed Spill Jet transport in 2001.

the DSO transport, shifted slightly forward in time. The two series reach maximum correlation $\left(r=0.33, p<10^{-7}\right)$ when lagged by $6 \mathrm{~h}$.

The Spill Jet defined by the PTF05 cyan box has two disadvantages: 1) it sometimes underestimates the transport, because it omits the jet along the lower part of the slope, and 2) it sometimes overestimates the transport when other shallow high-speed jets overlap (e.g., the surface cyclone in Fig. 12a). Hence, to overcome these problems, we consider a second definition $Q_{2}$ that (i) encloses a wider area (viz., the green box in Fig. 14) and (ii) employs a Richardson number threshold of $\mathrm{Ri}<1$ to select those areas of active vertical mixing. This transport definition corresponds to the definition of the Spill Jet itself in section $3 c(1)$, although it ignores the first criterion of being recently spilled, which is hard to implement automatically.

As expected, $Q_{2}$ results in larger transport estimates because it includes the deeper parts of the jet (Fig. 15c).
The averaged Spill Jet transport value is now $-4.9 \pm 1.7 \mathrm{~Sv}$, with maximum values exceeding $-9 \mathrm{~Sv}$. Maximum correlation between the two transport estimates is attained for a lag of $12 \mathrm{~h}\left(r=0.54, p<10^{-19}\right.$, and $Q_{2}$ lags $\left.Q_{1}\right)$. This finding is attributed to the type II events and explained with the following reasoning. The eddy structures associated with the dense DSO pulses occupy the Spill Jet section for about one day. For example, the leading edge of the surface cyclone shown in Fig. 11 induces spilling at 1800 UTC 9 August. It takes another $12 \mathrm{~h}$ for the cyclone to reach the section and a similar period to recede (not shown). During this period, spilled waters are mixing with waters traveling with the cyclone, as sketched in Fig. 13. When the spilling begins, the transport is low and increasing. When the cyclone occupies the section, waters denser than $\sigma_{\theta}=27.80 \mathrm{~kg} \mathrm{~m}^{-3}$ occupy most of the slope, but they do not contribute to either $Q_{1}$ or $Q_{2}$. It takes on average $6 \mathrm{~h}$ for the $\sigma_{\theta}=27.80 \mathrm{~kg} \mathrm{~m}^{-3}$ 
surface to move away from the shelf break and to be replaced by lighter water. Then, $Q_{1}$ peaks. It takes another $12 \mathrm{~h}$ for $\sigma_{\theta}=27.80 \mathrm{~kg} \mathrm{~m}^{-3}$ isopycnal to move away from the deeper parts of the slope, and then $Q_{2}$ peaks. Consistent with this argument, the correlation between $Q_{2}$ and DSO transport peaks when $Q_{2}$ lags by $18 \mathrm{~h}(r=0.18, p<0.004)$.

Both $Q_{1}$ and $Q_{2}$ show that Spill Jet maxima are more frequent than DSO transport maxima, because type I events do not involve DSO boluses. To distinguish the two types of spilling, $Q_{2}$ estimates exceeding the average value are denoted by different colors in Fig. 15c. Those that lag DSO maxima by $18 \mathrm{~h}$ are assigned to type II and plotted in red. Otherwise, the peaks are assigned to type I and plotted in green. Only DSO maxima exceeding the average DSO transport value are included. Note that this distinction is sensitive to the lag used. For example, the large transport value $\mathrm{X}$ in Fig. $15 \mathrm{c}$ does not count as type II because it lags DSO peak X by $24 \mathrm{~h}$ and not $18 \mathrm{~h}$. Nevertheless, a sharp, unambiguous distinction is probably impossible, given the complexity of the spilling process. Our criterion using time lags suggests that type II events are slightly more frequent than type I events, occurring in $57 \%$ of cases.

Type I events could be related to the local wind. To explore this idea, Fig. 15d shows the spatially averaged alongshore wind stress component for the period considered. The average is over the area enclosed in the black rectangle of Fig. 1a. Positive (negative) values indicate upwelling (downwelling) favorable conditions assuming a steady, linear Ekman layer applies. Strong downwelling winds may induce spilling because they may advect the dense, near-bottom shelf waters offshore (toward the shelf break) while moving shallower Atlantic waters onshore. The summer wind stress values shown in Fig. 15d correspond to relatively weak winds compared to winter. Averaged winds exceeding $10 \mathrm{~m} \mathrm{~s}^{-1}$ occur only during the first 15 days of July. The wind stress does not exhibit peaks that match the green type I peaks in Fig. 15c. This result is consistent with the findings of Haine et al. (2009), where no simple relation between the Ekman flux and the shelfbreak transport has been found (cf. their Fig. 11). A significant correlation $(r=$ 0.43 and $p<10^{-11}$ ) is found when the full $Q_{2}$ time series lags the wind by 2 days, which suggests that the spilling response to winds is indirect and delayed. Type II events are mediated by DSO pulses, which are not well correlated with the wind (the maximum correlation is for a lag of 9.5 days; $r=0.23$ and $p=0.001$ ), however. For these reasons the simple idea that local wind-driven Ekman fluxes force spilling is undermined, at least for the summer period. However, storms are more frequent and winds are significantly stronger during winter (e.g., Moore and Renfrew 2005; Harden et al. 2011), so wind-induced spilling may occur then.

\section{4) VORTICITY STRUCTURE}

Finally, to illuminate the unstable nature of the Spill Jet, the potential vorticity structure is diagnosed from the model fields following the analysis of the data in PTF05. The Ertel potential vorticity $\Pi_{E}$ can be written as

$$
\Pi_{E}=-\frac{(2 \boldsymbol{\Omega}+\boldsymbol{\nabla} \times \mathbf{v})}{\rho_{0}} \cdot \nabla \sigma_{\theta}=-\underbrace{\frac{f}{\rho_{0}} \frac{\partial \sigma_{\theta}}{\partial z}}_{\mathcal{A}} \underbrace{-\frac{1}{\rho_{0}}\left(\frac{\partial v}{\partial x}-\frac{\partial u}{\partial y}\right) \frac{\partial \sigma_{\theta}}{\partial z}}_{\mathcal{B}}+\underbrace{-\frac{1}{\rho_{0}}\left[\left(\frac{\partial w}{\partial y}-\frac{\partial v}{\partial z}\right) \frac{\partial \sigma_{\theta}}{\partial x}+\left(\frac{\partial u}{\partial z}-\frac{\partial w}{\partial x}+f^{*}\right) \frac{\partial \sigma_{\theta}}{\partial y}\right]}_{\mathcal{C}},
$$

where $x$ and $y$ are the zonal and meridional coordinates, $z$ the vertical upward coordinate, $\sigma_{\theta}$ the potential density, $\mathbf{v} \equiv(u, v, w)$ is the velocity field, $2 \boldsymbol{\Omega} \equiv(0,2 \Omega \cos \phi, 2 \Omega \sin \phi) \equiv\left(0, f^{*}, f\right)$ is the planetary vorticity at latitude $\phi$, and $\rho_{0}$ is the reference density. In quasigeostrophic theory, Eq. (1) reduces to terms $\mathcal{A}$ and $\mathcal{B}$. For large-scale flows that are not quasigeostrophic, those contributions in $\mathcal{C}$ that involve $w$ or $f^{*}$ can be neglected, as in Hall (1994). Using the thermal wind relation, Eq. (1) then becomes

$$
\Pi_{E} \simeq \underbrace{-\frac{f}{\rho_{0}} \frac{\partial \sigma_{\theta}}{\partial z}}_{\mathcal{A}} \underbrace{-\frac{1}{\rho_{0}}\left(\frac{\partial v}{\partial x}-\frac{\partial u}{\partial y}\right) \frac{\partial \sigma_{\theta}}{\partial z}}_{\mathcal{B}} \underbrace{-\frac{g}{\rho_{0}^{2} f}\left[\left(\frac{\partial \sigma_{\theta}}{\partial x}\right)^{2}+\left(\frac{\partial \sigma_{\theta}}{\partial y}\right)^{2}\right]}_{\tilde{\mathcal{C}}}
$$

where $g$ is the gravitational acceleration. Term $\mathcal{A}$ is the planetary stretching term and reflects the changes in vorticity due to the vertical stretching or compression of the isopycnals. Changes in the vertical component of the 

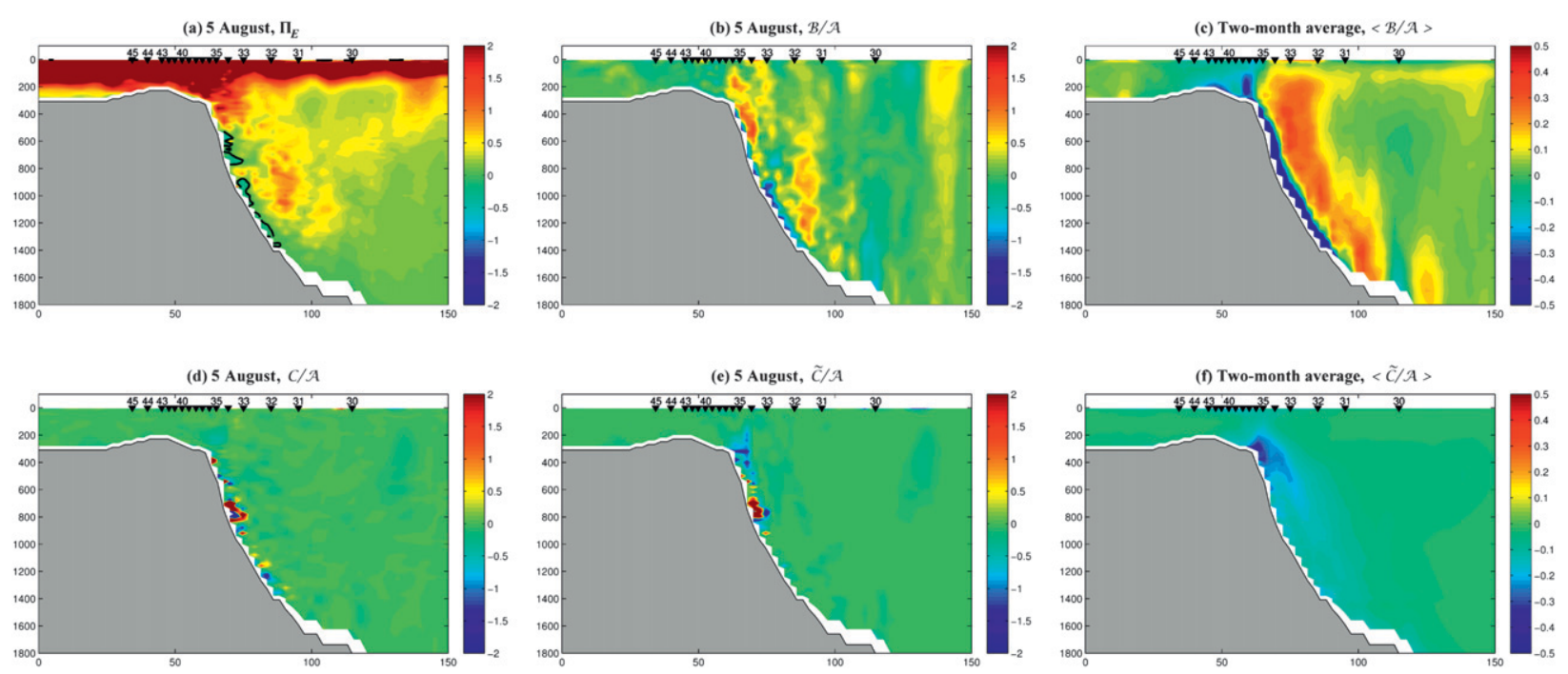

FIG. 16. Vertical model Spill Jet sections for (a) the Ertel potential vorticity on 5 Aug $\left(10^{-10} \mathrm{~m}^{-1} \mathrm{~s}^{-1}\right)$; the ratios (b) $\mathcal{B} / \mathcal{A}$, (d) $\mathcal{C} / \mathcal{A}$, and (e) $\tilde{\mathcal{C}} / \mathcal{A}$ on $5 \mathrm{Aug}$; and the averaged terms (c) $\langle\mathcal{B} / \mathcal{A}\rangle$ and (f) $\langle\tilde{\mathcal{C}} / \mathcal{A}\rangle$ during the two months. See text for the definitions of the different terms. The black line in (a) is the zero line. Note that the color bar limits change between panels. Numbers indicate 5-6 Aug station locations.

relative vorticity directly affect $\Pi_{E}$ via term $\mathcal{B}$, whereas term $\tilde{\mathcal{C}}$ is known as the tilting term. Term $\mathcal{A}$ usually dominates for large-scale flows, but all three terms have been shown to be important in regions with strongly tilted isopycnals (e.g., Hall 1994).

On 5 August, the model Ertel potential vorticity reaches large values at the surface, where it is dominated by the planetary stretching term (Fig. 16a). Along the slope, $\Pi_{E}$ is negative in some places, indicating that the fluid is unstable to symmetric overturning (Haine and Marshall 1998). Figure 16 (middle) shows the model vertical sections for the ratios of relative $(\mathcal{B}$; Fig. 16b) and tilting vorticity $(\tilde{\mathcal{C}}$; Fig. $16 \mathrm{e})$ to the planetary stretching term $(\mathcal{A})$ for the same day. The ratio $\mathcal{B} / \mathcal{A}$ is the vertical component of the relative vorticity, scaled by $f$. It reaches values close to \pm 2 along the slope, specifically at depths near 500 and $1200 \mathrm{~m}$ (Fig. 16b). Not surprisingly, these are the locations where the two Spill Jet cores are identified in Fig. 8d. Such a strong horizontal vorticity is 4 times larger than observed by PTF05 in 2001 but in line with other occupations of the section (Brearley et al. 2011, manuscript submitted to Deep-Sea Res.), reinforcing the notion that the Spill Jet may be barotropically unstable. Baroclinic instabilities are also expected to play a major role (e.g., Smith 1976; Jiang and Garwood 1996). The ratio $\mathcal{B} / \mathcal{A}$ is negative at the seabed because the lateral no-slip condition is imposed on the material boundary and, where $\mathcal{B} / \mathcal{A}<-1$, the fluid is inertially unstable (Haine and Marshall 1998). The simplified ratio based on thermal wind shear $\tilde{\mathcal{C}} / \mathcal{A}$ scales as $\sim \mathrm{Ri}^{-1}$ and large $\tilde{\mathcal{C}} / \mathcal{A}$ values indicate shear instabilities. The ratio $\tilde{\mathcal{C}} / \mathcal{A}$ reaches values close to -2 at the shelf break, near the upper Spill Jet core (Fig. 16e): that is, where the isopycnals are strongly tilted (cf. Fig. 8a). Note that $\tilde{\mathcal{C}}$ is always negative, but its ratio to $\mathcal{A}$ can be positive and large in the few grid points where the water column is vertically unstable $\left(\partial \sigma_{\theta} / \partial z\right.$ is positive and small). On 5 August, this happens along the slope at about $800 \mathrm{~m}$, in the area between the two Jet cores.

When the thermal wind relation is not used and no contributions are neglected in $\mathcal{C}$, the same unstable area centered at $800 \mathrm{~m}$ is evident in the ratio $\mathcal{C} / \mathcal{A}$ (Fig. 16d). The negative values near the shelf break, however, are smaller in magnitude $(\simeq-0.5)$, indicating that the horizontal component of vorticity is overestimated by the thermal wind relation.

Further analysis shows that the vorticity structure during the other days is qualitatively similar to that on 5 August and that all terms are significant at the Spill Jet section. Maximum values for the $\mathcal{B} / \mathcal{A}$ ratio usually follow the vertical displacements of the Spill Jet along the slope. Similar values are also associated with the strong horizontal shear because of the presence of DSO waters. The Spill Jet waters are often unstable to symmetric overturning $\left(\Pi_{E}<0\right)$, inertial instability $(\mathcal{B} / \mathcal{A}<-1)$, and gravitational overturning $(\tilde{\mathcal{C}} / \mathcal{A}>0)$. The averaged scaled vertical vorticity $\langle\mathcal{B} / \mathcal{A}\rangle$ over the full 2-month simulation shows cyclonic vorticity along the entire slope (Fig. 16c). The comparison with Fig. 14 suggests that the upper part extending from the shelf break to about $1200 \mathrm{~m}$ is due to the Spill Jet, whereas the lower part is due to the overflow. The averaged $\langle\tilde{\mathcal{C}} / \mathcal{A}\rangle$ term (Fig. 16f) is everywhere negative, indicating that, on average, the fluid is statically stable. The $\langle\tilde{\mathcal{C}} / \mathcal{A}\rangle$ values are also 
smaller in magnitude at the upper continental slope than $\tilde{\mathcal{C}} / \mathcal{A}$ on 5 August, because sometimes the tilting of the isopycnals is reduced there (as on 9 August; not shown).

\section{Conclusions}

In this study, results from a high-resolution $(\sim 2 \mathrm{~km})$ numerical simulation of the Irminger Basin circulation during summer 2003 are presented. The focus is primarily on the East Greenland Spill Jet, a recently discovered component of the Irminger Basin western boundary circulation that affects the exchange of properties between Arctic- and Atlantic-origin waters. Although the first synoptic view presented by PTF05 provided a basic description of the jet, many questions remain about its cause and its variability. This work provides a first extended-intime view of the phenomenon.

The results show that the model faithfully reproduces the qualitative surface state of the ocean inferred from satellite fields, as well as the general hydrographic structure and variability of the Denmark Strait overflow seen in the observations. Model fields compare well with observed water-mass transects in the basin. In particular, good correspondence is found between the model results and the observations taken during 2003 in the same location where the Spill Jet was first observed downstream of the Denmark Strait.

The numerical results reveal new aspects of the phenomenon. The Spill Jet is the result of the interplay of complex processes, which vary over time on periods of 0.1-10 days. For the same reason, the Spill Jet is subject to high variability. The notion of the Spill Jet presented here extends considerably the view available from the single snapshot provided by PTF05 in 2001. For example, the model demonstrates that spilling can occur in multiple locations southwest of the strait and that deeper Spill Jet cores can arise from waters previously spilled that descended the slope while being advected downstream.

Spilling and large Spill Jet transports are due to two basic types of events. In the first case (type I; Fig. 13, top), the jet arises from dense waters spilling off the Greenland shelf, presumably initiated by local perturbations in the turbulent flow. In the second case (type II; Fig. 13, bottom), the spilling is caused by cyclonic eddies imbedded in the shelfbreak hydrographic front that are linked to dense overflow domes at depth. Type II spilling is thus an integral part of a more complex process, and its time scale is dictated by the DSO variability. It is shown that, during summer 2003, type II events occur slightly more often than type I events. In light of these model results, the PTF05 snapshot probably captured a type I event.

Even though the spilling process is highly variable, the Spill Jet is evident in almost all of the sections considered.
This is because spilling also occurs at locations upstream of the Spill Jet section. Therefore, at least during summer 2003 , the model jet is a permanent feature. It can reach depths exceeding $1300 \mathrm{~m}$ (Fig. 8d), but the average depth for the lower bound of the inner core is about $1200 \mathrm{~m}$ (Fig. 14). The PTF05 definition for computing the model Spill Jet transport yields $-1.8 \pm 0.6 \mathrm{~Sv}$, similar to the synoptic estimate from the 2001 observations. This definition sometimes underestimates the transport, because it excludes the lower portion of the average model jet. An alternative transport definition, using a larger crossstream area and a Richardson number threshold $(\mathrm{Ri}<1)$, gives $-4.9 \pm 1.7 \mathrm{~Sv}$, close to the transport of the dense overflow waters at the same location. In this respect, the importance of the Spill Jet was likely underestimated by PTF05 because the model Spill Jet transport is similar to the DSO transport. Hence, the Spill Jet may be one of the main processes by which Atlantic and Arctic waters mix in the Irminger Basin. The vorticity analysis suggests that the jet is unstable to multiple growing modes and that baroclinic, barotropic, inertial, shear and symmetric instabilities may all play an important role.

Our study addresses the variability and kinematics of the Spill Jet. The role of the Spill Jet in the volume budget of dense waters south of Denmark Strait, the energy conversions in the spilling process, and questions about controlling mechanisms and seasonality are deferred to future work. Nevertheless, our results provide some dynamical insight. Spill Jet type II events are related to the passage of surface cyclones and dense DSO pulses. Other factors are involved for the type I events, but there is no obvious relation with the local along-shelf wind during summer. The wind may have an indirect effect by inducing turbulent perturbations, which induce the spilling. Finally, this study was limited to the summer of 2003, when sea ice was not present. Future numerical simulations will include the effect of sea ice and will explore the Spill Jet dynamics during a full annual cycle.

Acknowledgments. The research is supported by the National Science Foundation Grants OCE-0726393 and OCI-0904640 (MGM and TWNH) and OCE-0726640 (RSP). Insightful discussions regarding the observations with Wilken-Jon von Appen and Alex Brearley are acknowledged. Santha Akella is thanked for the initial help with the numerical setup. The authors also thank two anonymous reviewers for improving the manuscript. The simulations of this study were run thanks to the support of the Homewood High-Performance Cluster at the Institute of Data Intensive Engineering and Science of The Johns Hopkins University. 


\section{REFERENCES}

Adcroft, A., and J.-M. Campin, 2004: Rescaled height coordinates for accurate representation of free-surface flows in ocean circulation models. Ocean Modell., 7 (3-4), 269-284, doi:10.1016/ j.ocemod.2003.09.003.

_ C. Hill, and J. Marshall, 1997: Representation of topography by shaved cells in a height coordinate ocean model. Mon. Wea. Rev., 125, 2293-2315.

Bacon, S., G. Reverdin, I. G. Rigor, and H. M. Snaith, 2002: A freshwater jet on the east Greenland shelf. J. Geophys. Res., 107, 3068, doi:10.1029/2001JC000935.

Bruce, J. G., 1995: Eddies southwest of the Denmark Strait. DeepSea Res. I, 42, 13-29, doi:10.1016/0967-0637(94)00040-Y.

Campin, J.-M., A. Adcroft, C. Hill, and J. Marshall, 2004: Conservation of properties in a free-surface model. Ocean Modell., 6, 221-244, doi:10.1016/S1463-5003(03)00009-X.

Chapman, D. C., 1985: Numerical treatment of cross-shelf open boundaries in a barotropic coastal ocean model. J. Phys. Oceanogr., 15, 1060-1075.

Chassignet, E. P., and Coauthors, 2009: US GODAE global ocean prediction with the HYbrid Coordinate Ocean Model (HYCOM). Oceanography, 22, 64-75.

Da Silva, A., C. Young, and S. Levitus, 1994: Algorithms and Procedures. Vol. 1, Atlas of Surface Marine Data 1994, NOAA Atlas NESDIS 6, 83 pp.

Dickson, R. R., and J. Brown, 1994: The production of North Atlantic Deep Water: Sources, rates, and pathways. J. Geophys. Res., 99 (C6), 12 319-12 341.

Fox-Kemper, B., and D. Menemenlis, 2008: Can large eddy simulation techniques improve mesoscale-rich ocean models? Ocean Modeling in an Eddying Regime, Geophys. Monogr., Vol. 177, Amer. Geophys. Union, 319-338.

Griffiths, R. W., 1983: Internal wave drag and the production of intense vortices by turbulent gravity currents, with implications for the sinking of bottom waters. Ocean Modell., 50, 9-12.

Haine, T. W. N., 2010: High-frequency fluctuations in Denmark Strait transport. Geophys. Res. Lett., 37, L14601, doi:10.1029/ 2010 GL043272.

_ , and J. Marshall, 1998: Gravitational, symmetric, and baroclinic instability of the ocean mixed layer. J. Phys. Oceanogr., 28, 634-658.

—, S. Zhang, G. W. K. Moore, and I. A. Renfrew, 2009: On the impact of high-resolution, high-frequency meteorological forcing on Denmark Strait ocean circulation. Quart. J. Roy. Meteor. Soc., 135, 2067-2085, doi:10.1002/qj.505.

Hall, M. M., 1994: Synthesizing the Gulf Stream thermal structure from XBT data. J. Phys. Oceanogr., 24, 2278-2287.

Harden, B. E., I. A. Renfrew, and G. N. Petersen, 2011: A climatology of wintertime barrier winds off southeast Greenland. J. Climate, 24, 4701-4714.

Jackett, D. R., and T. J. McDougall, 1995: Minimal adjustment of hydrostatic profiles to achieve static stability. J. Atmos. Oceanic Technol., 12, 381-389.

Jakobsson, M., R. Macnab, L. Mayer, R. Anderson, M. Edwards, J. Hatzky, H. W. Schenke, and P. Johnson, 2008: An improved bathymetric portrayal of the Arctic Ocean: Implications for ocean modeling and geological, geophysical and oceanographic analyses. Geophys. Res. Lett., 35, L07602, doi:10.1029/2008GL033520.

Jiang, L., and R. W. Garwood, 1996: Three-dimensional simulations of overflows on continental slopes. J. Phys. Oceanogr., 26, 1214-1233.
Jónsson, S., and J. Briem, 2003: Flow of Atlantic water west of Iceland and onto the north Icelandic shelf. Hydrobiological Variability in the ICES Area, 1990-1999, Vol. 219, ICES Marine Science Symposia, 326-328.

Kalnay, E., and Coauthors, 1996: The NCEP/NCAR 40-Year Reanalysis Project. Bull. Amer. Meteor. Soc., 77, 437-471.

Käse, R. H., J. B. Girton, and T. B. Sanford, 2003: Structure and variability of the Denmark Strait overflow: Model and observations. J. Geophys. Res., 108, 3181, doi:10.1029/ 2002JC001548.

Krauss, W., 1996: A note on overflow eddies. Deep-Sea Res. I, 43, 1661-1667, doi:10.1016/S0967-0637(96)00073-8.

Large, W. G., and S. Pond, 1981: Open ocean momentum flux measurements in moderate to strong winds. J. Phys. Oceanogr., 11, 324-336.

— over the ocean. J. Phys. Oceanogr., 12, 464-482.

, J. C. McWilliams, and S. C. Doney, 1994: Oceanic vertical mixing: A review and a model with a nonlocal boundary layer parameterization. Rev. Geophys., 32, 363-403, doi:10.1029/ 94RG01872.

Lea, D. J., T. W. N. Haine, and R. F. Gasparovic, 2006: Observability of the Irminger Sea circulation using variational data assimilation. Quart. J. Roy. Meteor. Soc., 132, 1545-1576, doi:10.1256/qj.05.77.

Leith, C. E., 1967: Diffusion approximation to inertial energy transfer in isotropic turbulence. Phys. Fluids, 10, 1409-1416, doi:10.1063/1.1762300.

_ 1996: Stochastic models of chaotic systems. Physica D, 98 (2-4), 481-491, doi:10.1016/0167-2789(96)00107-8.

Macrander, A., R. H. Käse, U. Send, H. Valdimarsson, and S. Jónsson, 2007: Spatial and temporal structure of the Denmark Strait overflow revealed by acoustic observations. Ocean Dyn., 57, 75-89, doi:10.1007/s10236-007-0101-x.

Marshall, J., A. Adcroft, C. Hill, L. Perelman, and C. Heisey, 1997: A finite-volume, incompressible Navier Stokes model for studies of the ocean on parallel computers. J. Geophys. Res., 102 (C3), 5753-5766.

Moore, G. W. K., and I. A. Renfrew, 2005: Tip jets and barrier winds: A QuikSCAT climatology of high wind speed events around Greenland. J. Climate, 18, 3713-3725.

Munk, W., L. Armi, K. Fischer, and F. Zachariasen, 2000: Spirals on the sea. Proc. Roy. Soc. London, 456A, 1217-1280, doi:10.1098/ rspa.2000.0560.

Pickart, R. S., M. A. Spall, M. H. Ribergaard, G. W. K. Moore, and R. F. D. Milliff, 2003: Deep convection in the Irminger Sea forced by the Greenland tip jet. Nature, 424, 152-156, doi:10.1038/nature01729.

_ D. J. Torres, and P. S. Fratantoni, 2005: The East Greenland Spill Jet. J. Phys. Oceanogr., 35, 1037-1053.

Renfrew, I. A., G. N. Petersen, D. A. J. Sproson, G. W. K. Moore, H. Adiwidjaja, S. Zhang, and R. North, 2009: A comparison of aircraft-based surface-layer observations over Denmark Strait and the Irminger Sea with meteorological analyses and QuikSCAT winds. Quart.J. Roy. Meteor. Soc., 135, 2046-2066, doi:10.1002/qj.444.

Ross, C. K., 1977: Overflow-73-Denmark Strait, Vol. 2: Moored instrument time series. Bedford Institute of Oceanography Tech. Rep. Data Series BI-D-77-5, 105 pp.

Rudels, B., E. Fahrbach, J. Meincke, G. Budéus, and P. Eriksson, 2002: The East Greenland Current and its contribution to the Denmark Strait overflow. ICES J. Mar. Sci., 59, 1133-1154, doi:10.1006/jmsc.2002.1284. 
Serreze, M. C., and Coauthors, 2003: A record minimum arctic sea ice extent and area in 2002. Geophys. Res. Lett., 30, 1110 doi:10.1029/2002GL016406.

Smagorinsky, J., 1963: General circulation experiments with the primitive equations: I. The basic experiment. Mon. Wea. Rev., 91, 99-164.

Smith, P. C., 1976: Baroclinic instability in the Denmark Strait overflow. J. Phys. Oceanogr., 6, 355-371.

Spall, M. A., and J. F. Price, 1998: Mesoscale variability in Denmark Strait: The PV outflow hypothesis. J. Phys. Oceanogr., 28, 15981623.

Steele, M., R. Morley, and W. Ermold, 2001: PHC: A global ocean hydrography with a high-quality Arctic Ocean. J. Climate, 14, 2079-2087.

Straneo, F., R. S. Pickart, and K. Lavender, 2003: Spreading of Labrador Sea Water: An advective-diffusive study based on Lagrangian data. Deep-Sea Res. I, 50, 701-719, doi:10.1016/ S0967-0637(03)00057-8.

Sutherland, D. A., and R. S. Pickart, 2008: The East Greenland Coastal Current: Structure, variability, and forcing. Prog. Oceanogr., 78, 58-77, doi:10.1016/j.pocean.2007.09.006.
Våge, K., R. S. Pickart, G. W. K. Moore, and M. H. Ribergaard, 2008: Winter mixed layer development in the central Irminger Sea: The effect of strong, intermittent wind events. J. Phys. Oceanogr., 38, 541-565.

Whitehead, J. A., M. E. Stern, G. R. Flierl, and B. A. Klinger, 1990: Experimental observations of baroclinic eddies on a sloping bottom. J. Geophys. Res., 95 (C6), 9585-9610.

Yashayaev, I., M. Bersch, and H. M. van Aken, 2007: Spreading of the Labrador Sea Water to the Irminger and Iceland basins. Geophys. Res. Lett., 34, L10602, doi:10.1029/ 2006GL028999.

Zhang, H.-M., J. J. Bates, and R. W. Reynolds, 2006: Assessment of composite global sampling: Sea surface wind speed. Geophys. Res. Lett., 33, L17714, doi:10.1029/2006GL027086.

Zhang, J., and D. Rothrock, 2000: Modeling Arctic sea ice with an efficient plastic solution. J. Geophys. Res., 105 (C2), 33253338 .

— - R. W. Schmitt, and R. X. Huang, 1999: The relative influence of diapycnal mixing and hydrologic forcing on the stability of the thermohaline circulation. J. Phys. Oceanogr., 29, 10961108. 